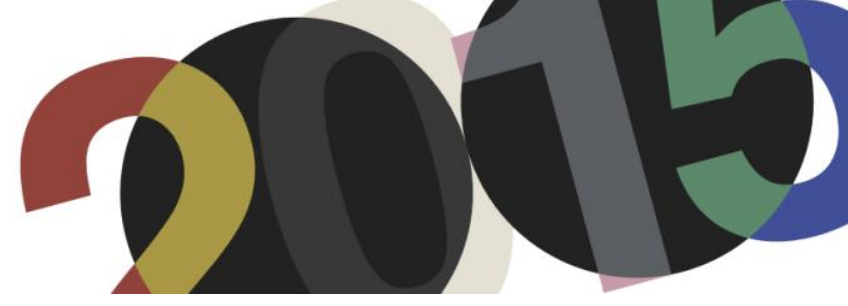

DOI: http://dx.doi.org/10.4995/LC2015.2015.582

\title{
La forme du temps à Moscou
}

\section{P. Ponce Gregorio}

Escuela Técnica Superior de Arquitectura de Valencia

Resumen: Sería el 2 de septiembre de 1931, mediante carta privada remitida por un tal B. Breslow en calidad de Representante Comercial de la URSS en Francia, cuando Le Corbusier recibe la invitación a participar en el concurso del que sería para muchos el edificio esencial del país, el Palacio de los Soviets de Moscú. Un edificio que en consecuencia, además de encarnar la voluntad de las masas trabajadoras rusas, debía convertirse de manera análoga, allí donde ya se hallaba construida la catedral de El Salvador, en el monumento artístico-arquitectónico de la todavía maltrecha capital soviética. Este y no otro es el punto en el que la presente «forma del tiempo» se inscribe: en el continuo devenir que el proyecto desarrolla dentro del número 35 de la rue de Sèvres de París, a fin de desempolvar parte de aquel rastro creativo velado por la historia, esto es, desandar la línea de los Soviets.

Abstract: It was around september the second, 1931, on a private letter dispatched by some B. Breslow acting as Comercial Representative of the URSS in France, when Le Corbusier received the invitation to participate in the contest of the one that would be for many the essential building of the country, the Palace of the Soviets in Moscow. A building that for that matter would not only enbodies russian's working class will, but also should become in the same way, there where the El Salvador cathedral was built, the artistic-architectural monument of the still struggling soviet capital. This and not else is the point in which the actual "shape of the time" it is enrolled: on the developed by the project inside the number 35 of the rue de Sèvres in Paris, in order to dust off part of that creative trace veiled by history, this is, to walk back along the line of the Soviets.

Palabras clave: Tiempo; composición; simbología; circulación; técnica; Palacio de los Soviets.

Keywords: Time; composition; symbology; circulation; technique; Palace of the Soviets.

\section{Introducción}

Entendemos el proyecto de arquitectura, sin que ello precise remedio, como una fuerza indeleble capaz de construir el pensamiento. Tiene el sentido fundamental de ese «primer esquema o plan de cualquier trabajo que se hace a veces como prueba antes de darle la forma definitiva», según el Diccionario de la Real Academia Española de la lengua. Es por tanto, si nos atenemos al núcleo duro del concepto, cuando encontramos en el proyecto una flamante herramienta para la arquitectura.

Ahora cabría preguntarse qué significa esto de proyecto de arquitectura, pues lejos de ser entendido como mera falacia, las respuestas parecen tener un punto de acuerdo contrapuesto y simétrico: mientras unos hablan de proyecto como realidad ya construida, otros como Zumthor, atendiendo a la etimología de la palabra, escribirán que proyectar significa inventar, un proceso no lineal que, partiendo de la historia de la arquitectura, conduzca, por así decirlo, a un nuevo edificio de un modo lógico y directo ${ }^{1}$.

Este y no otro es el punto en el que la investigación se asienta, en ese espacio de tangencia entre dos esferas tan diferentes como iguales, en esa dimensión donde pentagrama y notas musicales organizan el más ameno de los conciertos y redactan el mejor de los relatos. Interesa ese punto en el que proyecto y arquitectura estrechan lazos de amistad.

\footnotetext{
${ }^{1}$ Zumthor, Peter: Pensar la arquitectura. Barcelona: Gustavo Gili, 2010. pp. 22-23.
} 


\section{Sobre un proyecto de arquitectura}

Sería en ese momento preciso, una vez entendida la lógica del proyecto, cuando la investigación decidiera viajar a Moscú y acompañar a Le Corbusier en una de sus andanzas por la que entonces era la capital de la URSS. Proyecto y arquitectura debían asentar allí su sede para así, y sólo así, acercar posturas.

Un edificio invisible a la ciudad resultó ser centro de toda mirada, un edificio en la mente proyectado y en el plano construido. El trabajo decidió tropezar con un edificio que, alejado de toda realidad, aún conservara parte esencial de su idea; como si en la no construcción del mismo residiera su propio valor. Decidió tropezar por tanto, con lo que parece no ser nada más que un proyecto de arquitectura, el Palacio de los Soviets.

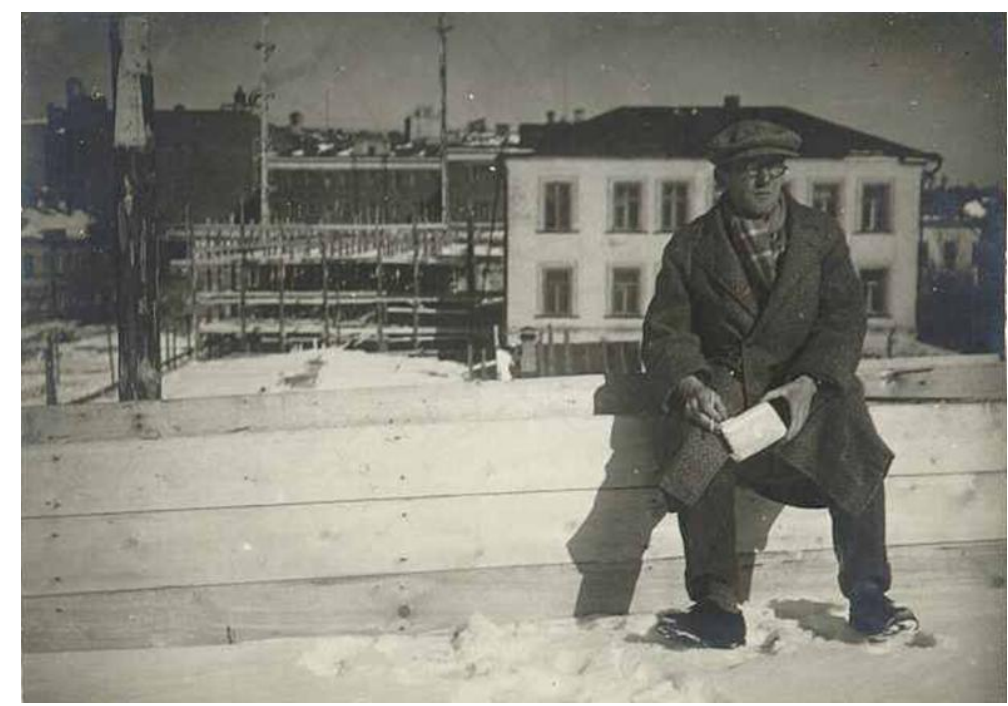

1. FLC_L4-4-162. Le Corbusier tomando anotaciones durante uno de sus viajes a Moscú, marzo de 1930. Fondation Le Corbusier - CFLC-ADAGP.

"Une matinée du mois de mars 1930. La neige couvre encore les immeubles de brique de Moscou. Drapé dans un large manteau de laine, sous une casquette de laine à larges bords et à visière enveloppante, Le Corbusier sourit, un petit carnet à la main. Le carnet est aujourd'hui perdu mais, à la place des échafaudages primitifs que l'on aperçoit à l'arrière-plan de la photographie, se dresse encore une construction de béton armé, de métal et de verre: le Centrosojuz, premier grand bâtiment qu'il a l'occasion de réaliser"’2.

A través de estas notas rápidas es como Le Corbusier pudo descifrar el código soviético ya desde el principio, pues pronto cayó en la cuenta de que el Palacio de los Soviets era capaz de superar la lógica misma para la que fue gestado. De hecho había quien hablaba de él, con muestras de un anacronismo heredado, como el «edificio esencial del país». Y es que el Palacio debía superar la lógica misma de su edificio, para combinar, con aparente naturalidad, el simbolismo característico de épocas pretéritas con el avance genuino de la modernidad.

${ }^{2}$ En castellano (traducción del autor), "Una mañana de marzo de 1930. La nieve cubre todavía los edificios de ladrillo de Moscú. Envuelto en un gran abrigo de lana, bajo una gorra de ala ancha e importante visera, Le Corbusier sonríe, una pequeña libreta en la mano. La libreta se ha perdido pero, en el lugar que ocupan los primitivos andamios del fondo de la fotografía, se alza todavía una construcción de hormigón armado, metal y vidrio: el Centrosoyus, primer gran edificio que tiene la oportunidad de realizar". Fragmento escrito por Jean-Louis Cohen describiendo una fotografía donde Le Corbusier toma notas en su primera visita a Moscú. Véase Cohen, Jean-Louis: Le Corbusier et la mystique de I'URSS. Théories et projets pour Moscou 1928-1936. Bruselas y Lieja: Mardaga, 1987. p. 9. (Fig. 1) 
Valgan por tanto estas palabras como reunión de ciertas nociones que, amparadas a la sentencia del proyecto, parecen formar parte del ardid ideado por el arquitecto:

\subsection{De la composición}

En marzo de 1991, Alan Colquhoun, quien fuera uno de los críticos de arquitectura más influyentes del último siglo, publica por primera vez su Modernidad y tradición clásica, libro que recopila alguno de los ensayos sin relación aparente escritos por él a lo largo de los años. Es en su segunda parte, bajo el sugestivo título de "Tradiciones y desplazamientos", donde sin ambages, da sus propias pinceladas en torno a Le Corbusier en general y el Palacio de los Soviets en particular.

Es justo ahí donde el autor, en buena lógica, da nombre a aquello de lo que ya apuntaba Choisy cuando precisamente hablaba de «la resolución artística de exigencias imprevistas». Pues la composición del plan corbusierano, según Colquhoun, «requería algo más que simplemente hacer que un edificio se conforme a las líneas limítrofes y a solares de forma irregular. Implicaba hacer entrar en juego un sistema de formas y masas en relación con un observador que ocupa posiciones específicas en el espacio; en una palabra, requería “composición"»?.

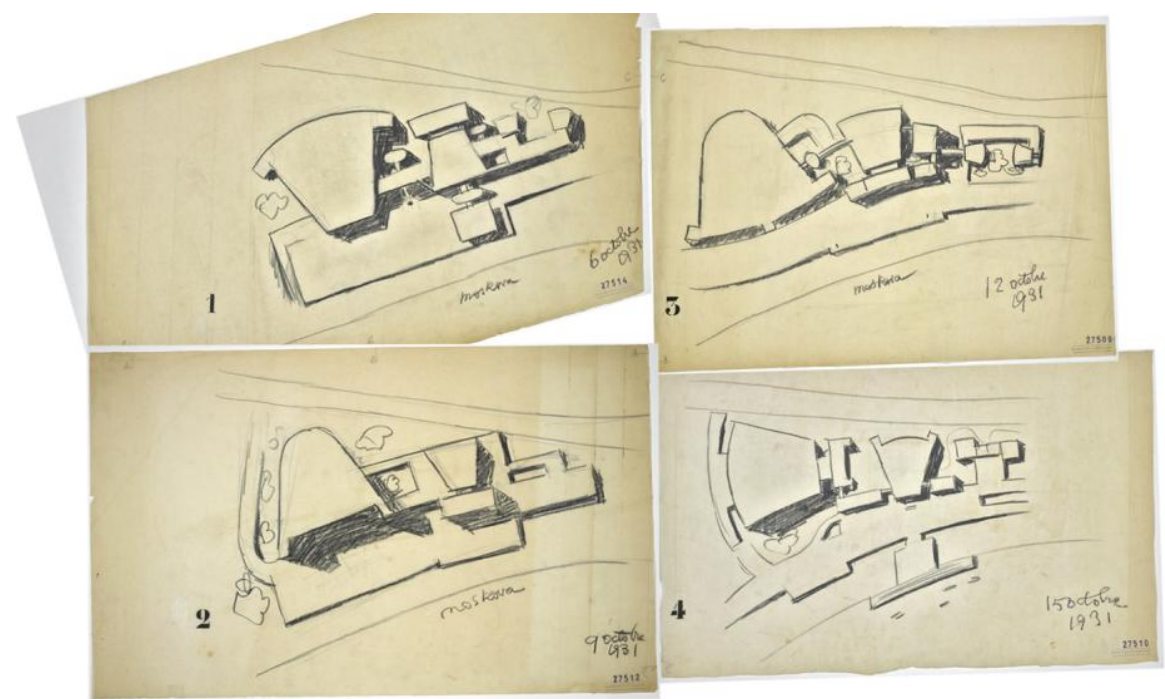

2. Primera parte del panel rotulado como PdS 2824 enviado a Moscú, el 19 de diciembre de 1931, como consecuencia del concurso del Palacio de los Soviets. Aparecen las supuestas cuatro primeras etapas del proyecto, desde el 6 al 15 de octubre de 1931. Los bocetos pueden encontrarse por separado en la Fondation Le Corbusier bajo las siguientes signaturas: FLC_27514, FLC_27512, FLC_27509 y FLC_27510 - OFLC-ADAGP.

El análisis de los bocetos y demás planos no cesan en dar indicios fehacientes de lo esquivas que a veces resultan ser las soluciones, pues, las sucesivas deformaciones no son sino huella de un proceso de concepción donde el plan, desprendiéndose de lo sobrante, optimiza el composto ${ }^{4}$ y reduce las formas a rastros elocuentes de un

\footnotetext{
${ }^{3}$ Colquhoun, Alan: Modernidad y tradición clásica. Madrid: Júcar Universidad, 1991. p. 168.

${ }^{4}$ En castellano (traducción del autor), compuesto. Es en el campo del arte y la arquitectura donde el término cobra otro sentido diferente pues, Composto o Bel Composto, término nacido para hablar de los interiores de iglesias, hará referencia a la composición que se genera entre pintura, escultura y arquitectura en el interior de los espacios sagrados.
} 
proceso creativo. Le Corbusier se presenta aquí como el arquitecto que proyectando un ideal solventa los pormenores del encaje urbano; la ciudad impone así su condición a una arquitectura que lucha por trascenderla ${ }^{5}$.

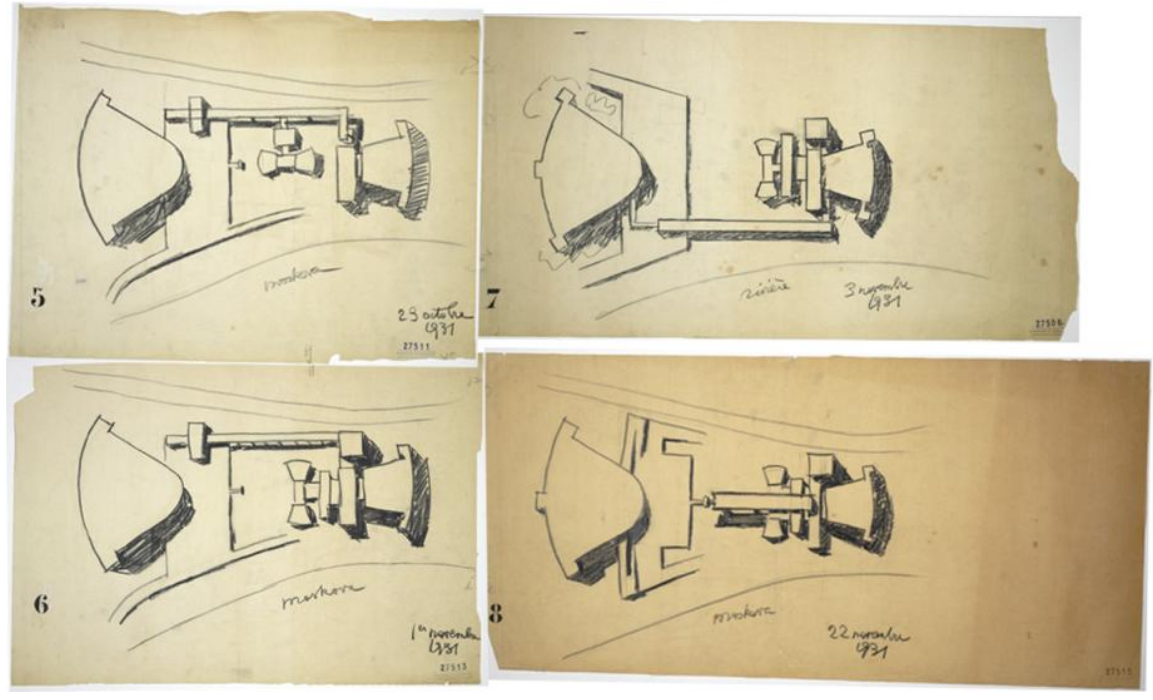

3. Segunda parte del panel rotulado como PdS 2824. Aparecen las cuatro últimas etapas, desde el 23 de octubre al 22 de noviembre de 1931. Los bocetos pueden encontrarse en la Fondation Le Corbusier bajo las siguientes signaturas: FLC_27511, FLC_27513, FLC_27506 y FLC_27515 - OFLC-ADAGP.

Es ahora, a través del trazo tosco y poco cuidado del arquitecto, cuando la composición esboza su discurso y nos avisa de la argucia en la composición pues, si se estudian los planos por separado y se desprenden las fechas de los mismos, es cuando el texto modifica su tono e invierte sus términos. Entendamos ahora que Le Corbusier nos muestra su proceso compositivo desde el final, desde ese elemento óptimo sobre el que la composición se soporta; el último esbozo construido entorno al eje más prosaico que existe, el eje de simetría. Del que escribió en Vers une architecture:

"El eje es, quizás, la primera manifestación humana; es el medio de todo acto humano. El niño que vacila tiende al eje, el hombre que lucha en medio de la tempestad de la vida se traza un eje. El eje es el que pone orden a la arquitectura. Poner orden, es comenzar una obra. La arquitectura se establece sobre ejes. [...] La ordenación es la jerarquía de los ejes, por lo tanto, la jerarquía de los fines, la clasificación de las intenciones"

Y es que el eje que vertebra este último boceto es, quizás, lo primero que dibujó el arquitecto en el momento de querer transmitirnos su composición. A partir de ahí, y una vez sentada la base del plan, era cuestión de irle enturbiando el semblante al proyecto; como si el descomponer formara parte del proceso de composición, pues a veces, cada retroceso no es más que un avance en una dirección distinta.

Es llegados a este punto cuando no deja de extrañar la confianza que el arquitecto encomendaba al trabajo compositivo de la planta, pues tal y como dice Jorge Torres en "La arquitectura es la circulación”, no hay que olvidar que «Le Corbusier recibe la herencia de la tradición académica por la cual le plan, la planta, es la

\footnotetext{
${ }^{5}$ Castellanos, Raúl: Plan Poché. Barcelona: Arquia/Tesis No 36, 2012. p. 13. En cuyo prefacio se habla de la composición del plan de San Carlo alle Quatro Fontane, Roma, 1635-1641. Obra de Francesco Borromini (1599-1667).

${ }^{6}$ Le Corbusier: Vers une architecture. París: G. Crès, 1923. (Trad. esp.: Hacia una arquitectura. Barcelona: Poseidón, 1977. p. 151).
} 
generadora de la arquitectura y la que establece un orden previo. El orden de la planta, garantizaba una concepción precisa» ${ }^{7}$.
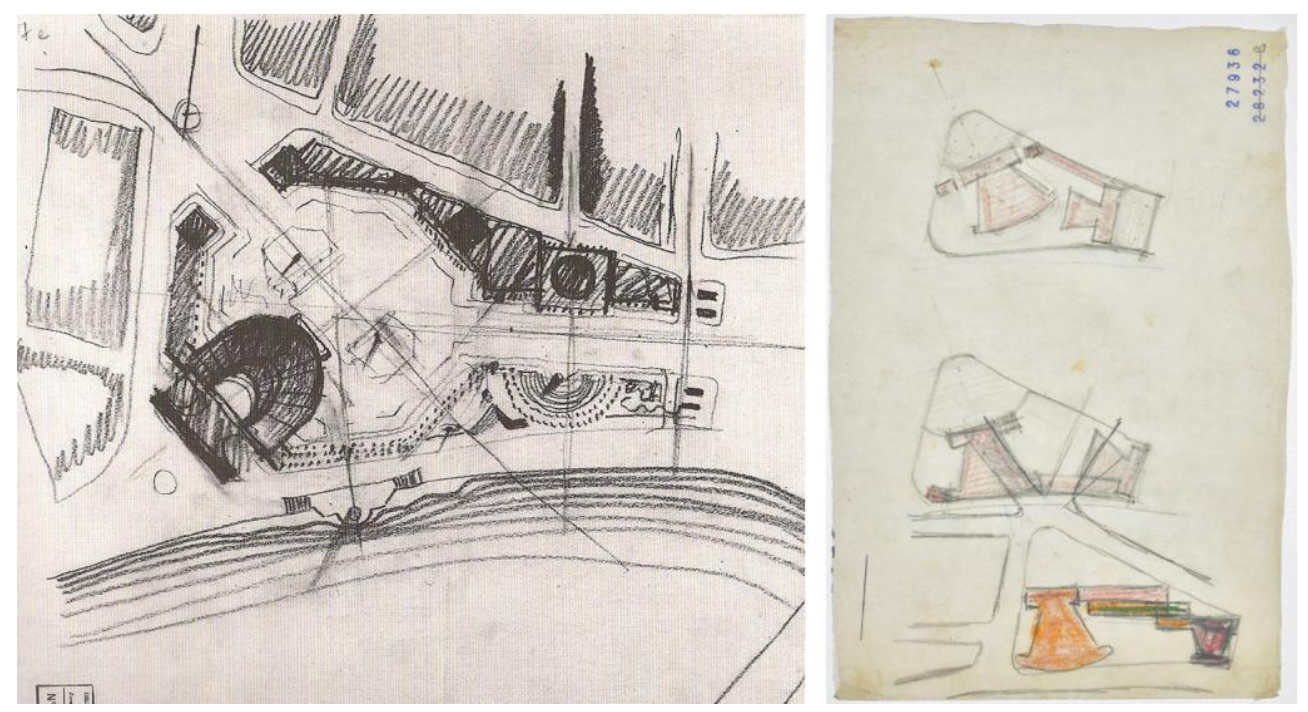

4. Uno de los bocetos iniciales de la propuesta de Auguste y Gustave Perret para la segunda convocatoria -por invitación- del Concurso del Palacio de los Soviets, 1931. Institut Français d’Architecture, París. // FLC_27936B. Tres bocetos iniciales de la propuesta de Le Corbusier, realizados entre el 1 y el 6 de octubre de 1931, en los que se estudian diferentes posibilidades de ocupación dentro de la parcela - OFLC-ADAGP.

Otros como Perret, por volver a la otra propuesta francesa presentada, confiarán también en la planta como mecanismo de composición elemental aunque con criterios aparentemente enfrentados. Pues Perret desde el principio quiso reconocer en su edificio aquella plaza que en su día circundaba la catedral de El Salvador, un espacio que, abrazando a un eje, obliga a la edificación a construir el perímetro que lo delimita. Y es que bien se podría decir que para Perret el eje era lo inevitable a evitar; el eje construía sin ser construido.

En cambio para Le Corbusier, tal y como revelan sus bocetos más incipientes, la construcción entorno al eje habría de ser condición fundamental. Y es que, de no ser esto cierto, a qué se deberían todas esas figuras simétricas gobernadas en algunos casos por líneas que cruzan sus mitades, sino a una suerte de ley que redefine al eje como lo inevitable a no evitar. De hecho, a propósito de la visita que el arquitecto realizara 20 años atrás a la casa del Poeta trágico en Pompeya, asevera en Vers une architecture que todo tiene su eje: «el eje está en las intenciones y en la dignidad que este confiere a las cosas humildes que en él se acomodan. El eje no es aquí un elemento teórico, sino una herramienta capaz de unir los volúmenes capitales» ${ }^{8}$.

Es por eso que Le Corbusier, sistematizando la disciplina de la arquitectura hasta la más postrera de sus consecuencias, hallara explicación lógica al decurso de su plan, esto es, concediera a cada pieza del programa un tamaño distinto y preciso donde la planta, reducida ya a formas simples, terminara por conformar una constelación de figuras distribuidas por la mano del arquitecto.

\footnotetext{
7 Torres, Jorge: "La arquitectura es la circulación". En Torres, Jorge (Coord.): Le Corbusier. Mise au point. Valencia: General de Ediciones de Arquitectura, 2012. p. 232.

${ }^{8}$ Le Corbusier: Vers une architecture. París: G. Crès, 1923. (Op cit. p. 153).
} 
Un eje imaginario, a veces recto, a veces quebrado ${ }^{9}$, sería el encargado por tanto de ordenar los continuos vaivenes del proceso compositivo del plan. Pues tal y como apunta Froebel, el que fuera referente del pequeño Jeanneret, es de esta manera como «el hombre ya desde su infancia busca un punto de unión, una unidad, en esa pluralidad de cosas particulares. Unión y unidad que, fundándose en una ley profunda y necesaria, haga comprensible la multitud desordenada de las cosas». Para más adelante apuntar que «el corazón del niño se tranquiliza con el presentimiento de esa unidad, pero su inteligencia no se satisface hasta que más tarde la descubre y conoce» ${ }^{10}$.

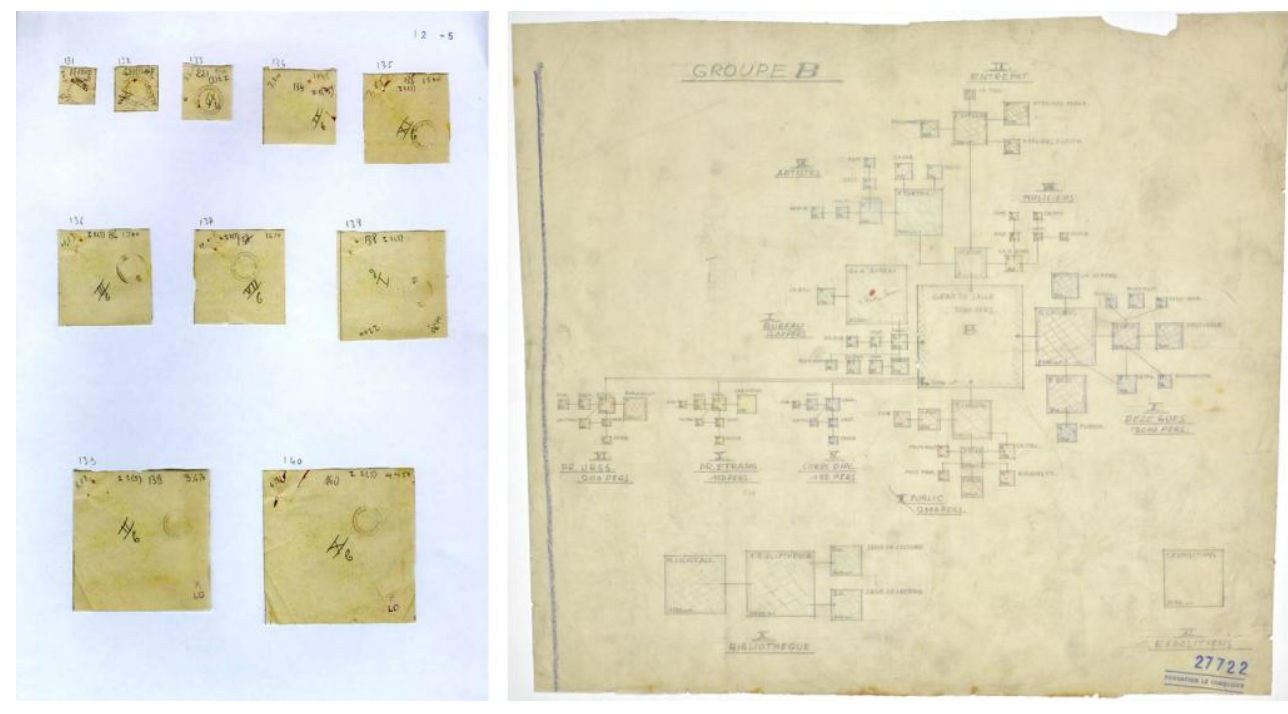

5. FLC_I2-5-104-004. Diferentes piezas recortadas por Le Corbusier correspondientes a los distintos paquetes de programa del grupo B del Palacio de los Soviets, 1931. Fondation Le Corbusier - OFLC-ADAGP. // FLC_27722. Organigrama funcional relativo al grupo B detallado en las condiciones generales de proyecto - OFLC-ADAGP.

Este, o similar, debió ser el exordio que hubo de inspirar a Josep Quetglas en uno de los pasajes de Le Corbusier Plans, donde escribe que «los ocho esquemas de Le Corbusier ayudan a entender el desarrollo intrauterino del proyecto aunque ya avisara de un falso camino para llegar a su arquitectura. La construcción de un violín es muy interesante, y el violín bien hecho está probablemente muy bien, pero no se debe confundir con la música que desprende» ${ }^{11}$.

\subsection{De la simbología}

París, 1931. Aquel eje tan manido y conocido procura ahora asir curvatura para a la vez izarse del plano en el que se hallaba recostado; debía desprenderse del seudónimo que le ocultaba, y, manifestando su excelencia, formar parte del mundo contingente de lo vertical. Debía darse a conocer y enaltecer las más puras manifestaciones de la arquitectura; debía ser construido y desvelado su verdadero nombre, arco.

\footnotetext{
${ }^{9}$ Ibídem, p. 153. Cuando, a propósito de la visita a la casa del Poeta trágico en Pompeya escribe: «todo tiene su eje, pero sería difícil pasar en línea recta. [...] Cuando se visita la casa del Poeta trágico, se constata que todo está en orden. Pero la sensación es rica. Se observan entones las deformaciones hábiles del eje que dan intensidad a los volúmenes».

${ }^{10}$ Froebel, Friedrich: La educación del hombre. Madrid: Daniel Jorro, Editor, 1913. p. 184. El que fuera pedagogo alemán creador de la educación preescolar e inventor de numerosos juegos de «composición elemental» mediante piezas simples como cubos, cilindros y esferas.

${ }^{11}$ Véase: “Le Corbusier. DVD Plans n4". En Quetglas, Josep: L'architecture. París: Fondation Le Corbusier, 2010. pp. 6-7. (Trad. esp.: La arquitectura). Cuando en la segunda parte habla del proceso compositivo corbusierano.
} 


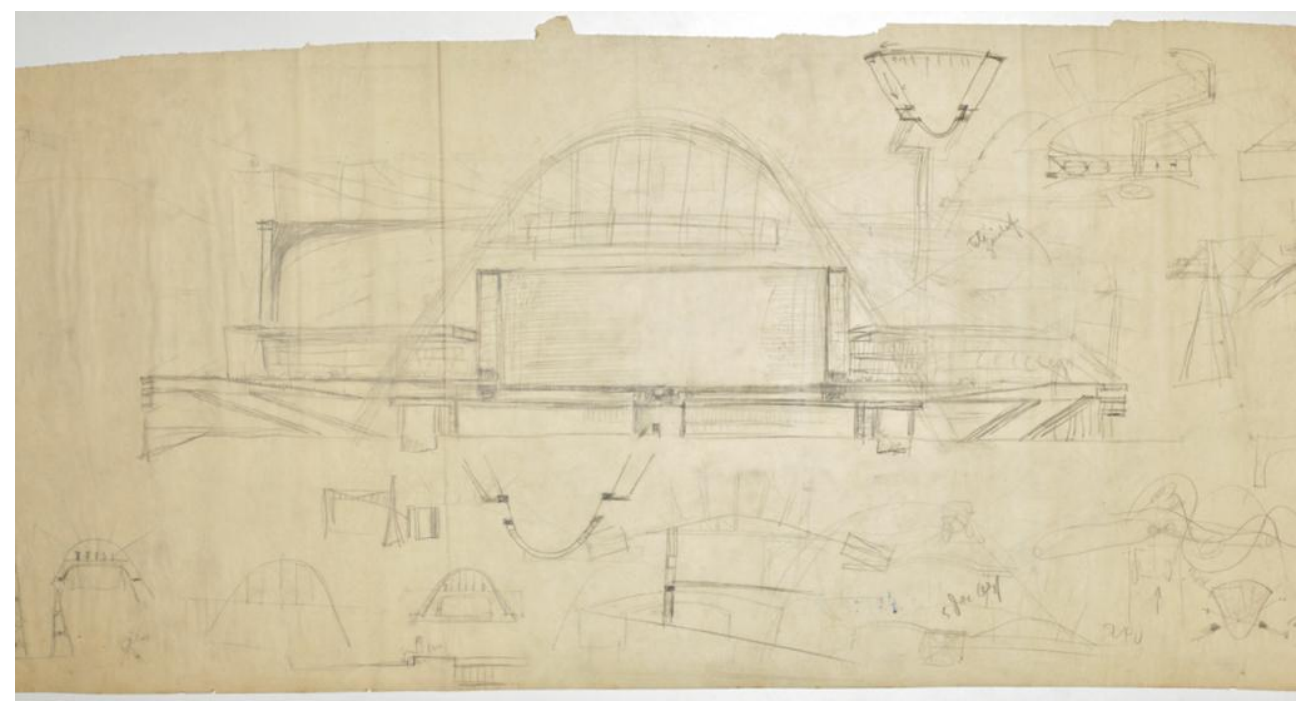

6. FLC_27494. Boceto fechado el 5 de diciembre de 1931 en el que Le Corbusier tantea el arco parabólico - OFLC-ADAGP.

$\mathrm{Y}$ es que entender que este trazo que soporta el Palacio es un eje curvado, no es más que obedecer a la etimología que nos educa el pensamiento, pues una de sus acepciones según el Diccionario de la Real Academia Española de la lengua, adoleciendo de cierta retórica, nos advierte a ser «sostén principal de una empresa».

El eje es para Le Corbusier orden y concierto, herramienta generosa; un elemento que sancionado por las leyes de la costumbre, apenas se hubo atrevido a transgredir la dictadura rígida de la composición. Pero el eje es además sinónimo de idea y designio, propósito o finalidad; una regla en torno a la cual se posibilita su entendimiento y construcción, el centro de toda cosa. Es por ello que, lejos de ser entendidos estos por Le Corbusier como trazados estrictos del plan, son realidades consumadas, pues «en la realidad los ejes no se perciben a vuelo de pájaro como los muestra el plano en la mesa de dibujo, sino sobre el suelo, cuando el hombre está de pie y mira al frente. El ojo ve incluso más allá de las intenciones y de las voluntades» ${ }^{12}$.

La vida de las formas no siempre ha avanzado al ritmo de los tiempos, sin embargo parece que en este arco parabólico el proceso sí se ha correspondido; pues surgiendo como consecuencia de la más absoluta necesidad, el arco se ha ido engalanando de alhajas, llenas todas de significado, para pronunciar en el Palacio el más poético de los discursos. Hay quien decía incluso que este arco no era más que mero homenaje a ciertas estructuras que Eugène Freyssinet venía construyendo desde hacía ya diez años: sea el caso de ciertos puentes, o los más que conocidos hangares para dirigibles de Orly; estructuras gestadas como fruto de la más absoluta necesidad parecen tener en el Palacio un significado bien distinto pues, según sostiene Josep Quetglas,

\footnotetext{
${ }^{12}$ Le Corbusier: Vers une architecture. París: G. Crès, 1923. (Op cit. p. 151).
} 

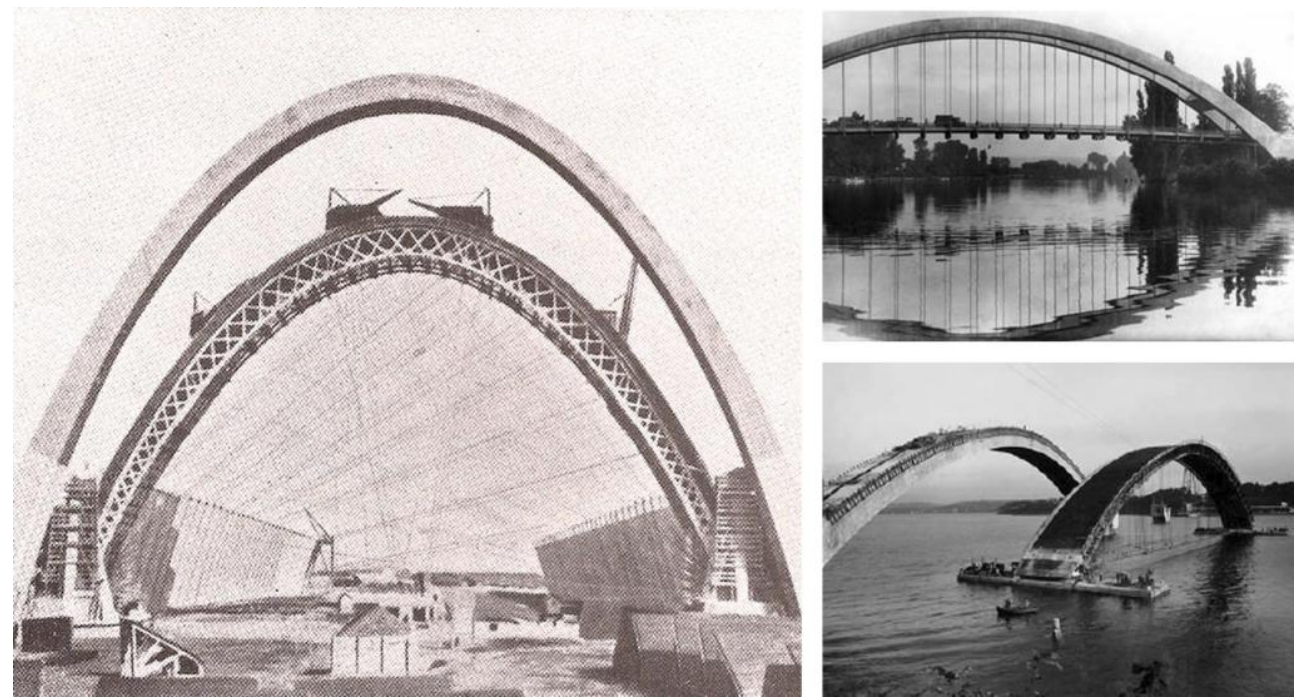

7. Construcción de uno de los arcos que terminarían por conformar los hangares para dirigibles de Orly, 1917-1921. Obra del ingeniero francés Eugène Freyssinet (1879-1962). // Puente de hormigón y acero construido sobre el río Sena a la altura de Saint-Pierre du Vauvray, 1923. // Desplazamiento de la cimbra del puente de Plougastel, 1925-1930.

"para entender la mirada de Le Corbusier sobre el arco de los Soviets hay que olvidar el hormigón y dirigirla a su primer viaje a Moscú, en 1928, cuando pone pie a tierra en la estación de Bielorrusia y dibuja el suelo curvo, los paneles de madera de la acera, la catedral, el arco de triunfo de la victoria sobre Napoleón, la maleta en el suelo, una caja, un carro y ... un caballo, con el collar habitual de las bestias de carga rusas, tanto en el campo como en la ciudad, que sorprenden al occidental. Se trata de un collar de madera clara, curvado en arco parabólico, que no toca el cuello del animal,"13.

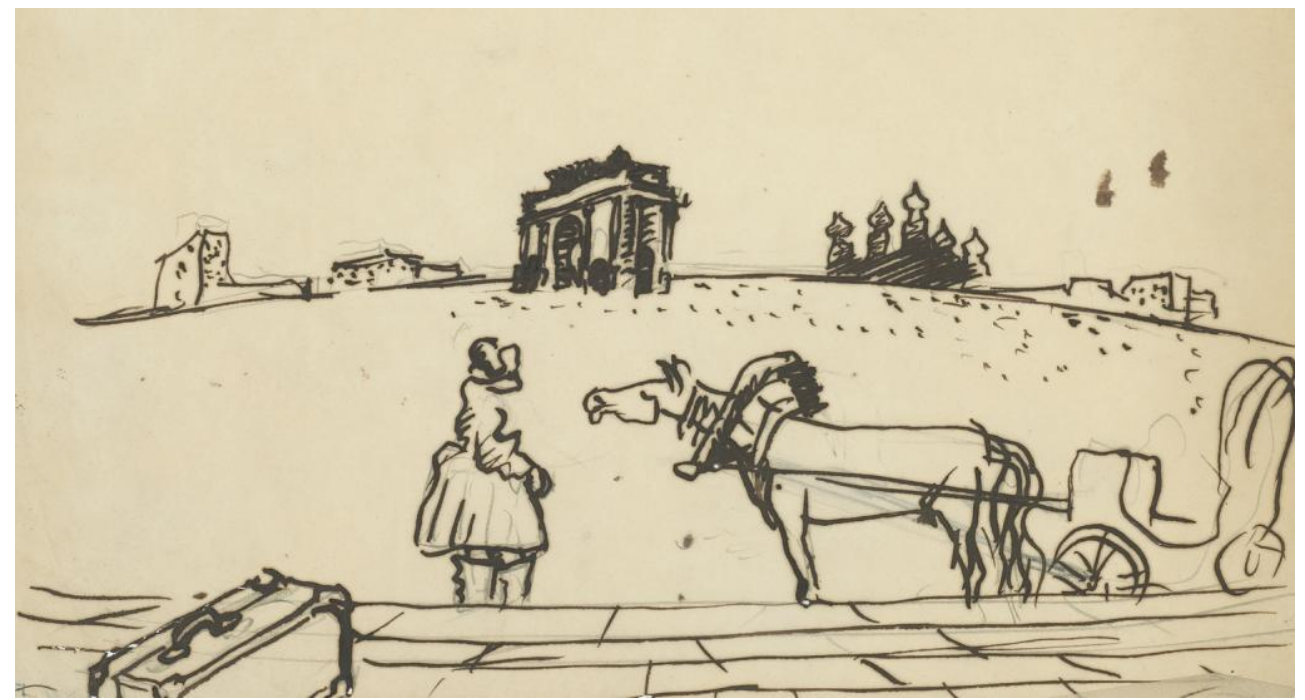

8. FLC_5540. Boceto realizado por Le Corbusier nada más llegar, en octubre de 1928, a la estación de Bielorrusia en Moscú. Donde aparece el Arco de Triunfo Osip Bove de la victoria sobre Napoleón y la silueta del muro del Kremlin junto a la Catedral de San Basilio - OFLC-ADAGP.

${ }^{13}$ Véase: "Le Corbusier. DVD Plans nº4". Op cit. pp. 8-9. (Fig. 8) 
A la vista de un boceto así, es donde uno se sorprende de la capacidad de mirar del arquitecto, pues es que ya desde el primer vistazo parecían estar asentadas las bases del proyecto. Bastaba el horcate que abrazaba el cuello del caballo para ver en ello el «segundo arco de triunfo de la ciudad» y hacer de esta historia una nueva página del libro de Le Corbusier, donde se nos muestra y define como un ser sin voluntad; como si nada fuese con él, con la única pretensión de ser mera hoja en blanco en la que la historia escribe ${ }^{14}$.

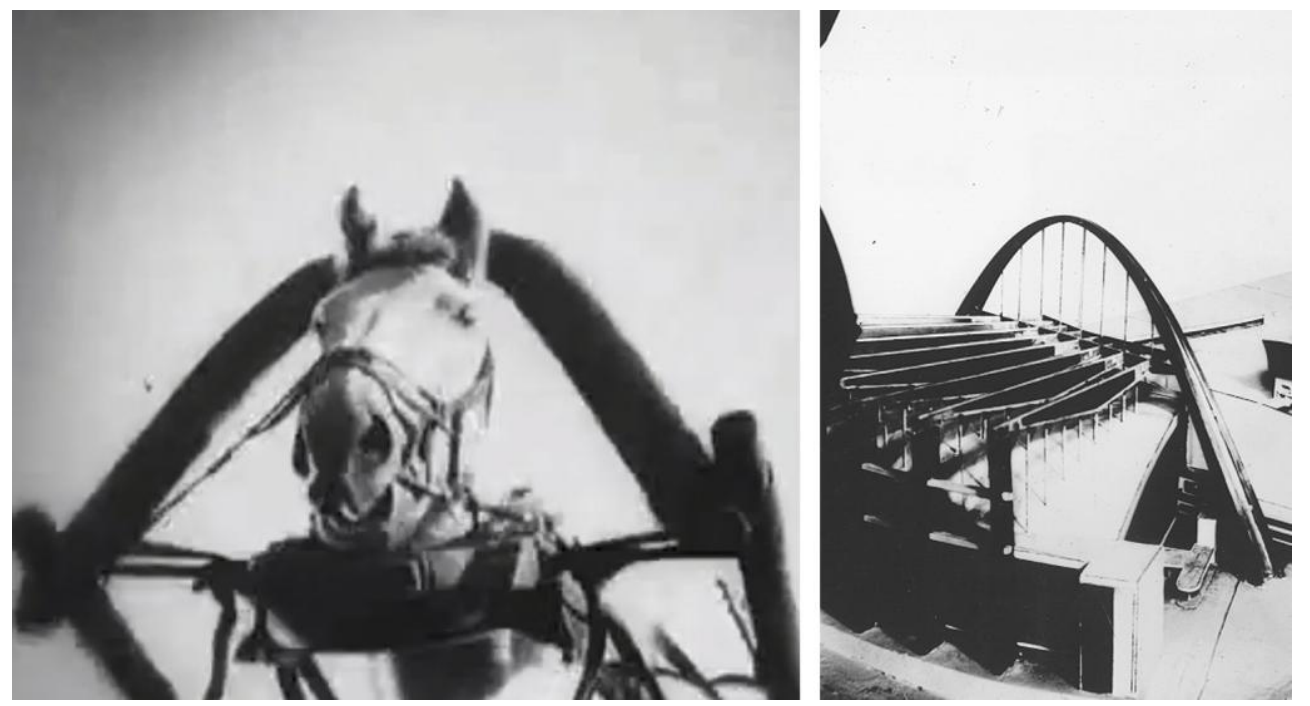

9. Fotograma de la película "La línea general", conocida en español como "Lo viejo y lo nuevo", donde se recalca la importancia del trabajo animal para el avance del hombre (min. 1,43,34), 1929. URSS. Dirigida por Serguéi M. Eisenstein (1898-1948). // FLC_L3-19-53. Fotografía de Lucien Hervé donde se muestra el arco parabólico que soporta la Sala A del Palacio de los Soviets, 1934. Fondation Le Corbusier - CFLC-ADAGP.

Pocos días pasaron desde su llegada «cuando Eisenstein le presentó (a Le Corbusier) unas bobinas de La línea general, donde los carros eran tirados por bueyes enganchados con estos mismos collares hasta pasar por delante de las cooperativas lecheras de arquitectura funcionalista» ${ }^{15}$.

Es ahora, haciendo provechoso el trance concedido por esta fortuita convergencia, cuando aquellos arcos de Freyssinet parecen no ser el motivo de la decisión, y sí, un sentimiento de nihilismo controlado el que dotase de luz al sistema, de hecho, es la similitud de ciertos planos de la película con fotografías de la maqueta lo que hace innegable la alianza entre esta arquitectura y el cine.

En efecto, y una vez asociado Le Corbusier a La línea general es cuando nada impide, aprovechando la amplitud que la imaginación siempre nos ofrece, asociar el esqueleto marcado en la piel de un animal todavía vivo con la estructura de las grandes salas de los Soviets; entendidos ambos como ramificaciones dependientes de un elemento regulador, sea la columna vertebral en el animal o el eje simétrico en el plan. En el que caso de que ya llegados a este punto de tangencia, no sean lo mismo.

\footnotetext{
${ }^{14}$ Véase la conferencia titulada "Immeubles-villas de Le Corbusier y arquitectura cartuja: constantes de proporcionalidad" a cargo de la arquitecta portuguesa Marta Sequeira el 24 de octubre de 2013 en la ETSAV; la cual, desmintiendo todo lo dicho por Le Corbusier en torno a la importancia que en él tenía la historia, planteaba la posibilidad de entender sus viajes como ratificación de un modelo ya preconcebido de antemano.

${ }^{15}$ Véase: "Le Corbusier. DVD Plans nº". Op cit. p. 9. (Fig. 9)
} 

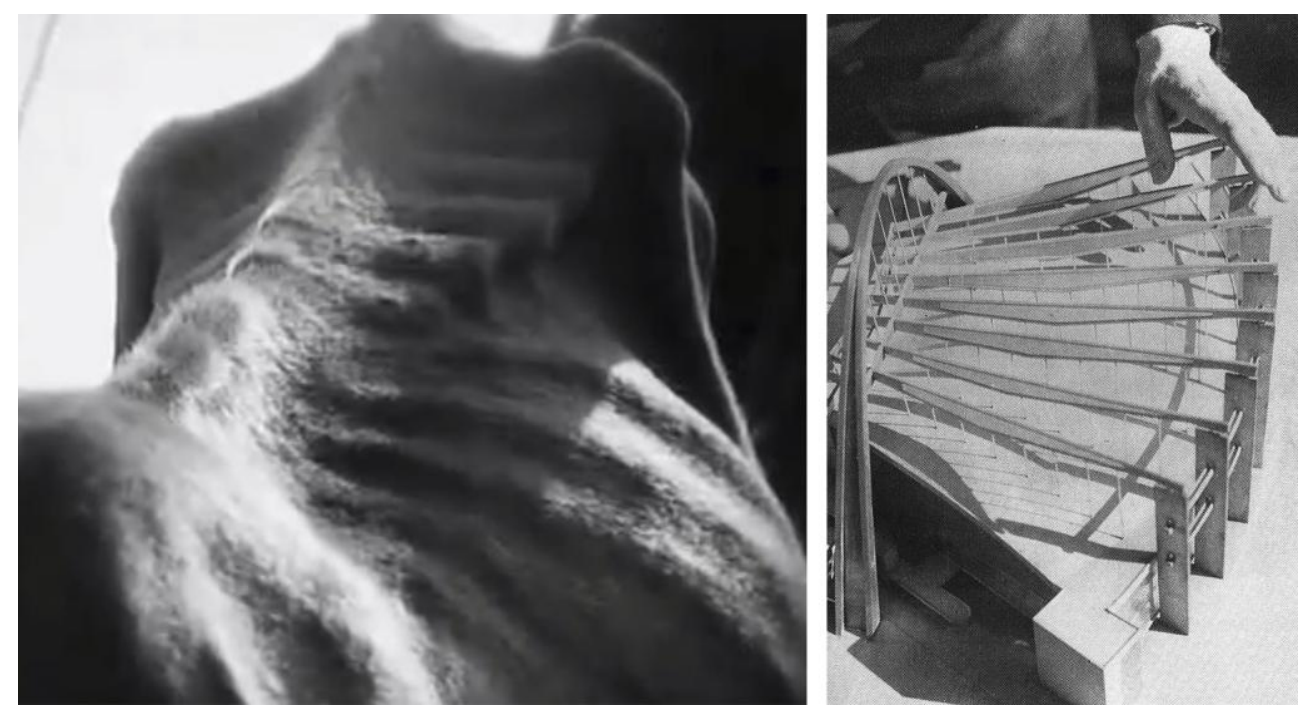

10. Instante de "La línea general" en el que, mediante un plano corto, se pretende mostrar la consecuencia que el trabajo supone a las «bestias de tiro» soviéticas (min. 0,10,18). // Fotografía de André Limot donde Le Corbusier manipula la cubierta de la Sala A del Palacio de los Soviets, 1934. Fondation Le Corbusier - OFLC-ADAGP.

El edificio pues, desde el arco a la estructura misma de las salas, no es otra cosa que reflejo de una sociedad abocada al fracaso que además, dada la contingencia, debía ajustarse el yugo y tirar de la cuadriga para así poder aspirar al más puro e inaccesible de los ideales. Y es que a pesar de los escombros y sucios andamios descuidados por doquier ya parecía alzarse, clara y nítida, la silueta de aquel edificio grandioso. La auténtica torre de Babel, aquella que no pretendía acercar a los hombres al cielo, sino el cielo a los hombres.
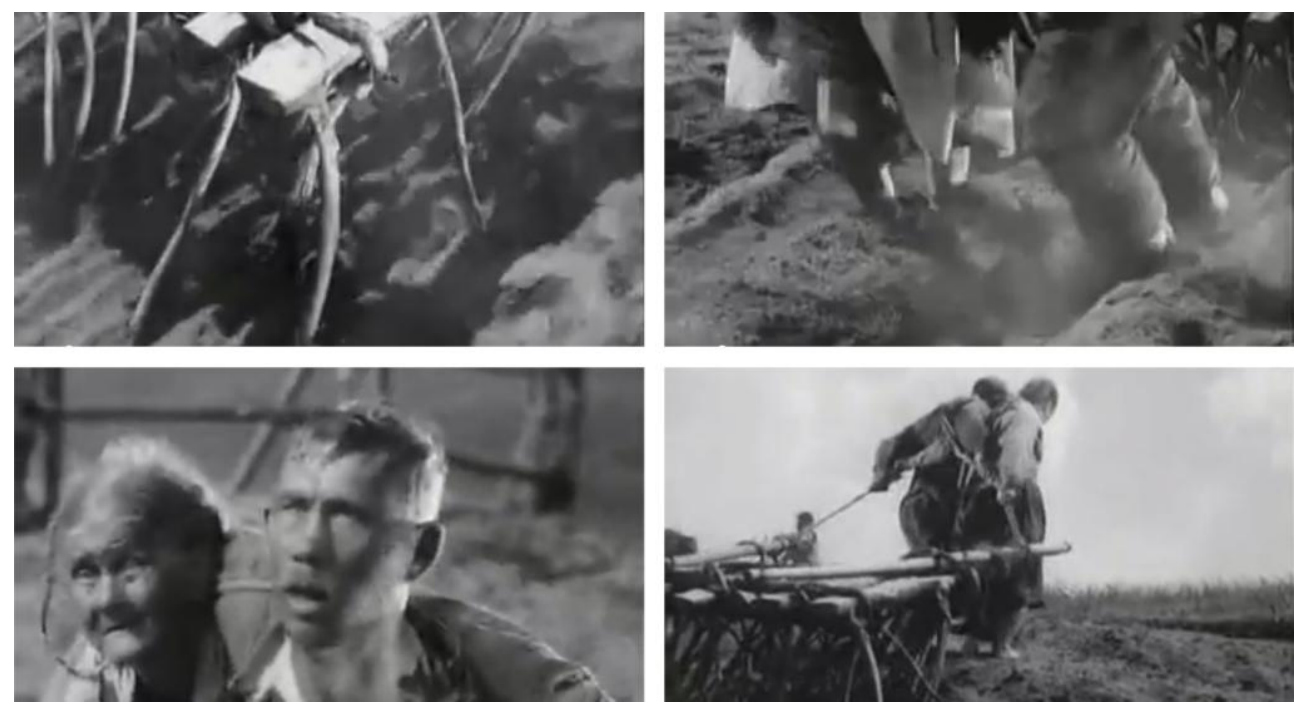

11. Secuencia de "La línea general" en la que se muestra el instante en que dos campesinos se ven obligados a tirar de los aperos de labranza justo después de la muerte de su animal (de arriba abajo y de izquierda a derecha: del min. 0,17,16, al min. $0,17,43)$. Momento en el que se ejemplifica la precariedad de las formas de trabajo soviéticas y el irrevocable anhelo de la sociedad por alcanzar la más elevada de las aspiraciones.

En este sentido, será de nuevo Josep Quetglas el encargado de manifestar aquel cariz que el Palacio de Le Corbusier quiso entregar al mundo: 
"No importa que el ruso pueda reconocer los trazos en la enorme escala de la URSS, de este nuevo gancho que debía tirar del país. El Palacio de los Soviets: no es un arco de triunfo del tiempo industrial, no es una escenografía pasiva y declamatoria, sino una herramienta para el trabajo y la acción que lleva lejos, una máquina para cambiar el mundo" ${ }^{\text {, }}$.

Pero sería llegados a este punto cuando el arquitecto, en lo que aparenta ser la prueba de un alzado todavía por resolver, dota de una nueva variable a la ecuación que venimos planteando. Y es que, en uno de los márgenes del papel es donde el yugo se convierte ahora en silla de montar para un Lenin que obligatoriamente debía presidir la composición -tal y como reclamaba aquel Consejo Ejecutivo al que se subordinó la propuesta ganadora-. No es de extrañar entonces que Le Corbusier, obcecado ya por la construcción del Palacio, modificara su discurso y convirtiera aquel horcate que debía tirar del país, en la montura de un Lenin invisible que reposaba sobre un animal encargado de representar el trabajo del hombre soviético, esto es, el Palacio de los Soviets.
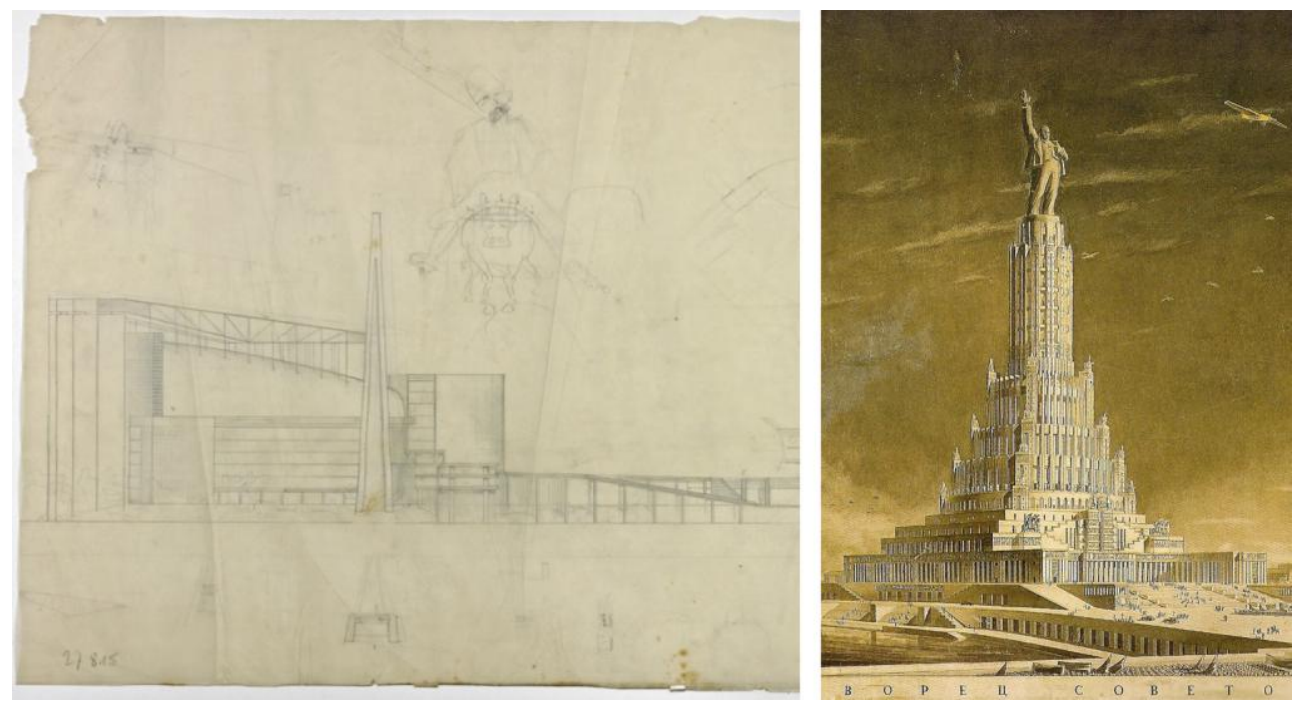

12. FLC_27815. Alzado longitudinal del Palacio de los Soviets visto desde el río Moskova. En el margen superior izquierdo, dibujo de la figura de Lenin sobre uno de los típicos animales de carga soviéticos - OFLC-ADAGP. // Perspectiva. Sexta convocatoria -cerrada-. Propuesta definitiva de Boris M. Iofan, Vladímir A. Shchuko y Vladímir G. Gelfreikh, 1931.

\subsection{De la circulación}

"Dibujo un personaje. Lo hago entrar en la casa; descubre su volumen, tal forma de habitación y sobre todo tal cantidad de luz que entra por la ventana o el panel de cristales. Avanza; otro volumen, otra llegada de luz. Más lejos, otra fuente luminosa; más lejos aún, inundación de luz y penumbra al lado, etc",l7.

Circular es caminar, moverse en derredor. Experimentar, descubrir y aprender incluso, es también circular. Un verbo cuya acción, circulación, le ha servido a la arquitectura para definir el interludio que permite poner de acuerdo sus estancias, y es que desde un punto de vista funcional qué es la circulación sino mero vehículo de conducción; un artilugio capaz de hacer funcionar la máquina más inexacta. De hecho, será Alexander Klein el que mediante sus estudios gráficos sobre vivienda destacase la importancia de estas circulaciones a la hora de

\footnotetext{
${ }^{16}$ Ibídem, p. 9.

${ }^{17}$ Le Corbusier: Précisions sur un état présent de l'architecture et de l'urbanisme. París: Éditions Vincent, Fréal et Cie, 1930. (Trad. esp.: Precisiones respecto a un estado actual de la arquitectura y el urbanismo. Barcelona: Poseidón, 1999. p. 154). Dentro del capítulo «El plano de la casa moderna», donde describe los bocetos número 121, 122. (Fig. 13a)
} 
alcanzar el "mínimo existencial" y así ratificar el pensamiento funcional más puro, es por ello que, «espacios de comunicación demasiado grandes y recorridos demasiado largos, derivados de una desfavorable distribución de la planta, provocan un aumento de superficie» ${ }^{18}$.

Podríamos decir entonces que la modernidad peor entendida, quedándose en lo somero de la cuestión, lucha por soltar lastre y desprenderse de aquello que a estas alturas parece no ser más que un trámite entre dos espacios que anhelan entrar en contacto. Como si en la no existencia de este tránsito radicara su propio éxito; para la arquitectura actual en palabras de Jorge Torres, «la circulación es lo inevitable a evitar» ${ }^{19}$.
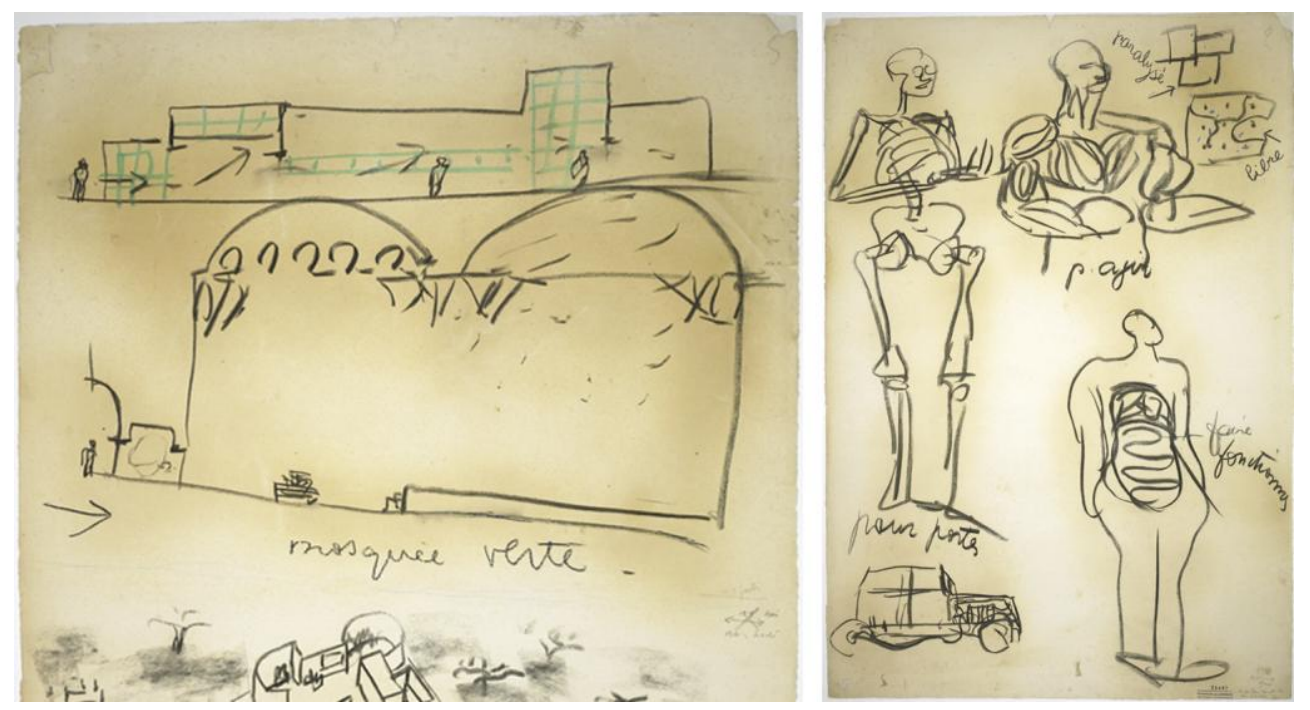

13. FLC_33493. Bocetos en los que Le Corbusier esboza su manera de entender el recorrido arquitectónico tomando como ejemplo la mezquita Verde de Brousse - OFLC-ADAGP. // FLC_33497. Comparativa del plan paralysé de la casa antigua con el plan libre de la casa de la modernidad - OFLC-ADAGP.

El 11 de octubre de 1929 fue viernes. Día de la quinta conferencia que Le Corbusier debía impartir en Buenos Aires a «los amigos de las artes», turno entonces de "el plano de la casa moderna" recogido en Précisions sur un état présent de l'architecture et l'urbanisme, donde el arquitecto, partiendo del plan paralysé $e^{20}$ de la casa de piedra, nos revela parte esencial de su parti ideal:

"Un poco de biología previa: este armazón para aguantar, unos rellenos musculares para actuar, esas vísceras para alimentar y hacer funcionar.

Un poco de construcción automóvil: un chasis, una carrocería, un motor con sus órganos de alimentación y de evacuación ${ }^{, 21}$.

\footnotetext{
${ }^{18}$ Klein, Alexander: Vivienda mínima: 1906-1957. Barcelona: Gustavo Gili, 1980. p. 33. Donde aporta un nuevo método de investigación sobre plantas de pequeñas viviendas.

${ }^{19}$ Torres, Jorge: "La arquitectura es la circulación”. Op cit. p. 213.

${ }^{20}$ En castellano (traducción del autor), planta paralizada. De esta manera Le Corbusier habla de la casa de la Academia al inicio de la quinta conferencia pronunciada en Buenos Aires a «los amigos de las artes», fechada el viernes 11 de octubre de 1929, comparándola con la planta libre de la casa de la modernidad.

${ }^{21}$ Le Corbusier: Précisions sur un état présent de l'architecture et de l'urbanisme. París: Éditions Vincent, Fréal et Cie, 1930. (Op cit. p. 146). Dentro del capítulo «El plano de la casa moderna», donde describe los bocetos número 111, 112, 113 y 114. (Fig. 13b)
} 
$\mathrm{Y}$ es que precisamente son esas mismas vísceras, ahora convertidas en ligeros conductos eléctricos y tubos metálicos, las que con intrínseca flexibilidad abrazan los órganos rígidos del vehículo esbozado en la parte inferior, justo en la esquina opuesta a dos plantas que pelean por acercar posturas: donde una, paralizada por el trazado grueso de su poché, se contrapone a la libertad de movimientos de un plan corbusierano amparado a la sentencia de la mobilité. Es ahora, una vez limada la más postrera de las asperezas, cuando se hace evidente la importancia que para el plan libre posee la circulación:

"L'architecture, c'est de la circulation".

«La arquitectura es la circulación» es el lema conque, mal traducido en la versión castellana como «la arquitectura es circulación», Le Corbusier en su segunda conferencia nos alerta de ella no como elemento a resolver la función, sino como herramienta capaz de otorgar validez a un plan que, a su vez, le permitiera ahondar en el trasfondo de la arquitectura y asentar las bases de su tratado. Cómo se explica sino, la frase que sigue a la ya escrita, y que la consuma diciendo:

"Mediten esta frase, -la circulación- condena los métodos académicos y consagra el principio de los pilotis",22.

Pues son esos mismos pilotis los que elevan el impulso de las intenciones y hacen del plano del suelo un continuиm donde lo natural permanece y la poesía queda intacta. Pero el piloti es también «la consecuencia del cálculo y el resultado elegante de la tendencia moderna a la economía -en este punto tomada en su sentido más noble-. Pilote: es atribuir a unos puntos determinados el cuidado de soportar, según un cálculo exacto, unas cargas precisas, sin ningún desperdicio» ${ }^{23}$.

El piloti será, por tanto, elemento sancionador y subversivo de toda creencia aún sujeta a la rigidez de la Academia, siendo la nueva técnica que lo construye, entendida como base misma del lirismo, la que permita esta nueva arquitectura en torno a una circulación libre por la que el hombre se desplaza. Tanto es así que Le Corbusier en 1929, bajo la dirección de Pierre Chenal, supo utilizar el cine como vehículo de explicación de su arquitectura ${ }^{24}$. L'arquitecture d'aujourd'hui de 10,19 minutos de duración, pasó a convertirse en su flamante herramienta donde tratar de desvelar ese nuevo espíritu para la arquitectura y el hombre que la examina. De hecho, en un momento preciso en que la cámara se eleva, es cuando Le Corbusier ratifica el modelo en no más de tres segundos; justo el tiempo que necesita un niño para con su bicicleta, desobedecer el rastro indeleble que el plan dibuja en el suelo, para sólo así, moverse con libertad en una suerte de gesto similar al que el arquitecto hubo de utilizar a la hora de diseñar el Palacio una vez esos mismos rastros ya se hallaban trazados. Y es que, como ya se apuntaba anteriormente, no hay que olvidar que «Le Corbusier recibe la herencia de la tradición académica por la cual le plan, la planta, es la generadora de la arquitectura y la que establece un orden previo. El orden de la planta, garantizaba una concepción precisa» ${ }^{25}$.

\footnotetext{
${ }^{22}$ Ibídem. p. 64. Dentro del capítulo «Las técnicas son la base misma del lirismo. Abren un nuevo ciclo de la arquitectura», correspondiente a la segunda conferencia fechada el 5 de octubre de 1929.

${ }^{23}$ Ibídem. p. 68.

${ }^{24}$ Colomina, Beatriz: "Reflexiones sobre la casa Eames”. En RA Revista de arquitectura. 2007, №9. Pamplona: Servicio de publicaciones de la Universidad de Navarra. p. 13.

${ }^{25}$ Torres, Jorge: “La arquitectura es la circulación”. Op cit. p. 232.
} 

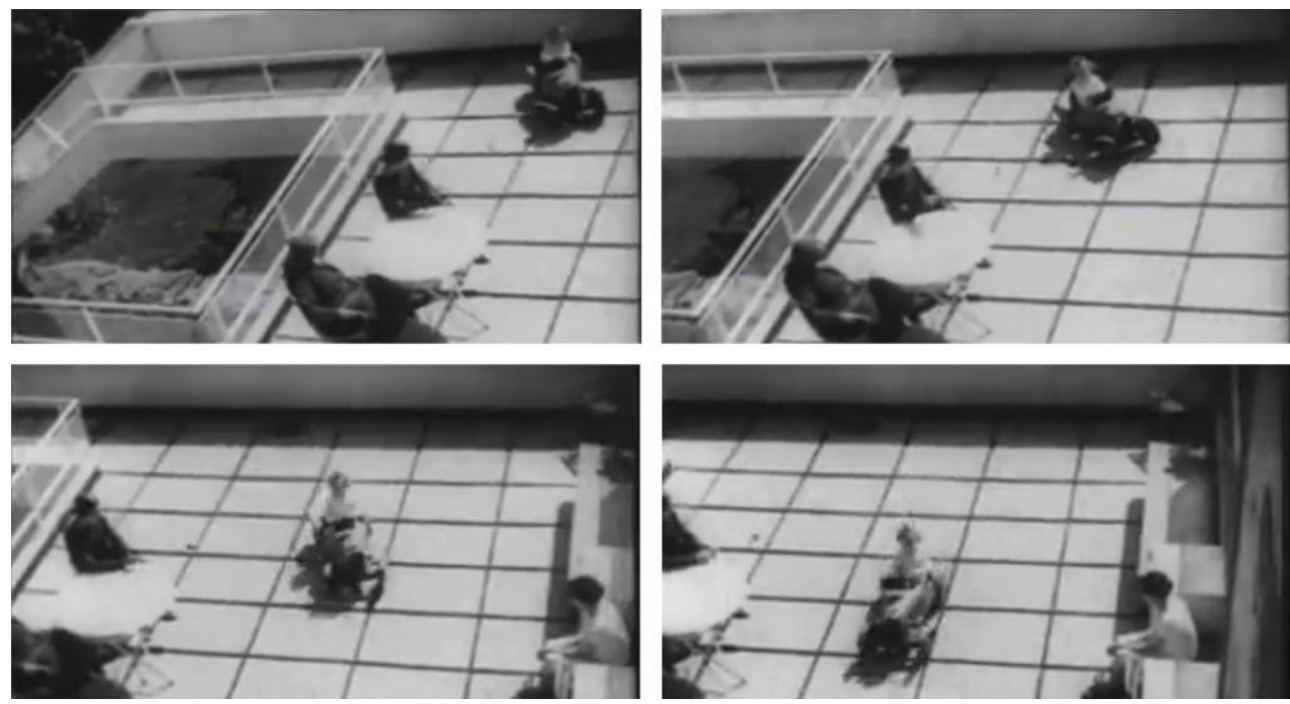

14. Fotogramas del inicio de la película "L'arquitecure d'aujourd'hui", donde se muestra cómo un niño circula con su triciclo por la terraza-jardín de la Villa Stein en Garches (de arriba a abajo y de izquierda a derecha: del min. 0,02,17, al min. 0,02,19). París. 1929. Dirigida por Pierre Chenal (1904-1990) y rodada en la Villa Savoye, la Villa Stein y la Villa d’Avray.

Si el piloti es el principio que posibilita la promenade, la escalera será para Le Corbusier el más torpe y egoísta de los elementos; un ente capaz de someter a todo aquel que aborde sus dominios pues, ya una vez dentro de su lógica, no cabe la distracción. El ser que se enfrenta a la escalera, olvidándose de lo que le rodea acompasa su cuerpo, y como un primoroso diapasón, mediante espasmos, negociará la contingencia que esta le presente.

Es, en el momento de resolver los edificios de gran envergadura cuando Le Corbusier se olvida del enaltecimiento espiritual que comporta la rampa en la casa y hará de ella la más funcionalista de sus herramientas. En esta línea, y a propósito del Palacio de los Soviets, escribe:

“Las escaleras tradicionales han sido reemplazadas por planos inclinados o rampas, único método para alcanzar velocidades suficientes ${ }^{, 26}$.

Llegados a este punto fundamental parece el movimiento para el «cuerpo del hombre», o algo de esto debió mover las leyes del pensamiento corbusierano pues, de no ser esto cierto, a qué se debería esa fuerte pregnancia en el recorrido dentro del que sería su proyecto idealizado; aquel capaz de darle forma al tiempo como esa cuarta dimensión imposible de alcanzar en el dibujo y que necesita por tanto de la palabra para entonces sí, poder expresarse.

La forma del tiempo para Le Corbusier es algo de esto: palabras y dibujos.

"Pasados los guardarropa, las 14.000 personas se encuentran en un plano inclinado que los conducirá, sin escaleras, con perfecta continuidad, bien sea a la Sala o aquellos lugares más remotos a través de las grandes entradas situadas a izquierda y derecha, o bien al gran Hall-forum situado bajo la sala.

El plano mismo que les conduce hasta allí, continua constante hasta alcanzar el anfiteatro de la misma sala. Este anfiteatro está alimentado por tres arterias -una central y dos laterales-, que se dividen ellas mismas en rutas secundarias horizontales y caminos verticales".

\footnotetext{
${ }^{26}$ Le Corbusier; Jeanneret, Pierre: Projet pour la construction du Palais des Soviets à Moscou. Memoria de presentación. Mecanografiada y correcciones autógrafas. Diciembre de 1931. FLC_H3-6-1-002.
} 


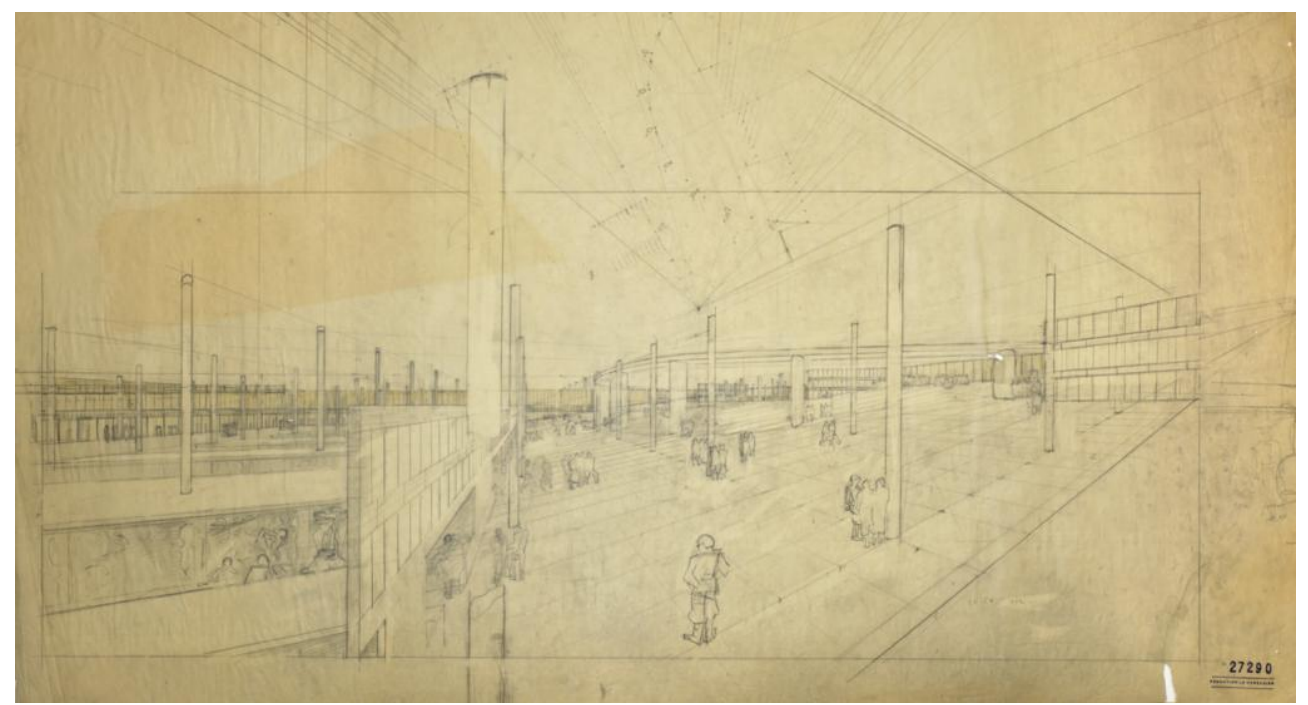

15. FLC_27290. Perspectiva del acceso a la Sala A previa al dibujo definitivo FLC_27251 - OFLC-ADAGP.

Y es, pocas líneas más tarde, cuando aquella biología ya anticipada en Précisions vuelve a entrar en escena, esta vez para comparar la circulación sanguínea del humano con la arquitectónica del edificio:

"La circulación de la sala está basada en un régimen circulatorio normal, con arterias, arteriolas, capilares",27.

Es ahora, si recordamos aquel organigrama que Le Corbusier confecciona a fin de ajustar la función de su edificio, cuando constatamos que el énfasis recae aquí en los contactos que se producen entre estancias, esto es, en el efecto coadyuvante que ejercen cada una de las piezas con sus vecinas más inmediatas. Pues qué duda cabe de que sólo mediante la estrategia representada por Le Corbusier en el dibujo, podría ya imaginarse esto como un procedimiento basado en el control que una serie de figuras dominantes ejercen sobre un sistema encargado de mediar entre la ciudad y el más pequeño de los reductos contenidos en el plan.

Es por tanto ahora, una vez aprendida la lógica del método, cuando el aspecto biológico del esquema no pasa inadvertido para todo aquel que con mirada analítica adivine sus atributos, pues qué es sino un corazón palpitante la silueta colocada en el centro de la composición que riega y dota de flujo al sistema, y qué es lo demás sino consecuencia lógica de la circulación intravenosa de un edificio cuyas estancias, al ritmo de la presión arterial, van reduciendo su escala hasta verse reducidas a mínimas células conectadas por capilares. Y es que la circulación corbuseriana, desinteresada ya por las escalas que enmarcan a la arquitectura, se define como «una gran palabra moderna. Todo es circulación en la arquitectura y el urbanismo» ${ }^{28}$.

Llegados a este punto, y una vez descrita la arquitectura como "la máquina a habitar", será el urbanismo el encargado de otorgar orden a todo efecto producto del desarrollo azaroso de la ciudad ${ }^{29}$. Aspecto este que Le Corbusier posteriormente describirá en su libro Urbanisme:

\footnotetext{
${ }^{27}$ Ibídem. FLC_H3-6-1-008. (Fig. 15)

${ }^{28}$ Le Corbusier: Précisions sur un état présent de l'architecture et de l'urbanisme. París: Éditions Vincent, Fréal et Cie, 1930. (Op cit. p. 150). Dentro del capítulo «El plano de la casa moderna», donde habla de la «circulación» como uno de los factores fundamentales a desarrollar junto a otros como -clasificación, dimensionamiento, composición y proporcionamiento-, en la revolución arquitectónica todavía por llegar.

${ }^{29}$ Le Corbusier; Jeanneret, Pierre: Projet pour la construction du Palais des Soviets à Moscou. Op cit. FLC_H3-6-1-036.
} 
"La calle es una máquina de circular; es una fábrica cuyos utensilios deben realizar la circulación. La calle moderna es un órgano nuevo. Es necesario crear tipos de calles que estén equipadas como está equipada una fábrica ${ }^{\prime 30}$.
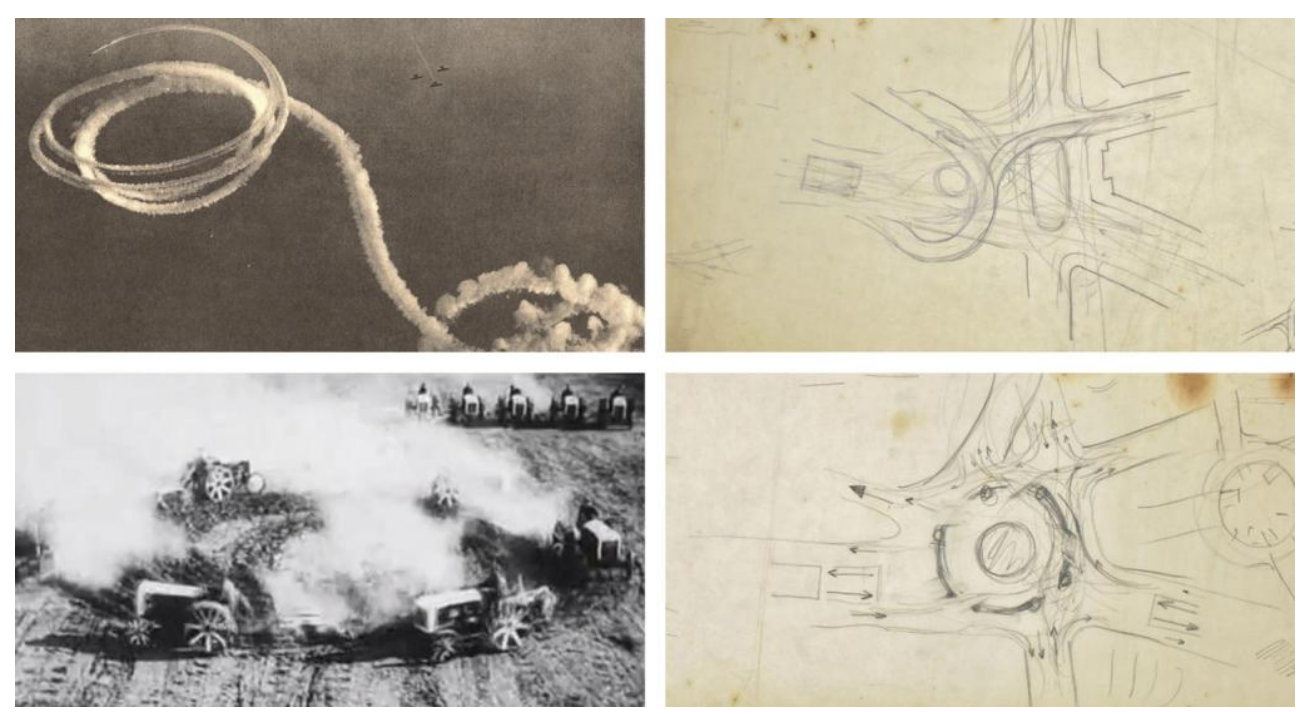

16. En la columna de la izquierda, de arriba a abajo: 1. Aviones italianos trazando anillos de humo: Extraído del libro de Le Corbusier "Aircraft". Madrid: Abada Editores, 2003. img. 83; 2. Tractores arando: min. 1,56,17 de "La linea general". En la columna de la derecha, de arriba a abajo: FLC_27453 y FLC_27501 - OFLC-ADAGP.

En ese sentido, parece legítimo afirmar que la calle a estas alturas no es más que "la máquina a circular". Una visión novedosa que permitirá a la técnica inmiscuirse en los asuntos más vulgares de la arquitectura, para de manera inapelable, resolver el principal problema que para Le Corbusier evidencia el urbanismo de su época: «reducir los tiempos muertos entre dos funciones fundamentales como son estar en casa -afectividad y descansoe ir a trabajar -oficinas-» ${ }^{31}$.

Y es que no es de extrañar que el ojo ciclópeo de Le Corbusier, observando las más puras manifestaciones técnicas que la física y la naturaleza conceden al mundo, se apoderase de un trazo obsesionado en resolver con movimientos el propio movimiento.

\subsection{De la técnica}

"La arquitectura es la manifestación del espiritu de una época que se aprovechó de sus conquistas técnicas. Confiere a lo que va a ser el rostro de la tierra un aire de juventud y honestidad que vivifica el espíritu, estimula la actividad creativa y establece los nuevos eslabones de la cadena ininterrumpida de la tradición, esa cadena en la que cada pieza es al mismo tiempo un acto de optimismo creativo, un paso adelante y un esfuerzo constructivo $^{, 32}$.

\footnotetext{
${ }^{30}$ Le Corbusier: Urbanisme. París: Éditions Vincent, Fréal et Cie, 1930, p. 126. También en L'Esprit Nouveau n²5. París: julio de 1925.

${ }^{31}$ Le Corbusier; Jeanneret, Pierre: Comentaires relatifs a Moscou et a la Ville Verte, marzo de 1930. FLC_H3-6-54-004.

${ }^{32}$ Le Corbusier: Aircraft. Madrid: Abada Editores, 2003. img. 27.
} 
Diríamos que Le Corbusier ve a cada momento cómo la arquitectura no cesa en manifestar aquellas necesidades acuciantes que la debilitan, esto es, se muestra predispuesta a nuevas sugerencias capaces estas de disolver el rastro de su propia involución. De hecho, será el mismo arquitecto el que reconozca en Précisions que sus «ideas revolucionarias están en la historia, en toda época y en todos los países» ${ }^{33}$. Él apenas ha inventado nada, si acaso actualizado todos esos principios de la memoria que siempre han acompañado los pasos de la arquitectura, y es que de no ser esto cierto, cómo se explica sino el título de su segunda conferencia pronunciada el sábado 5 de octubre de 1929 bajo el sugestivo título de "Las técnicas son la base misma del lirismo arquitectónico, abren un nuevo ciclo a la arquitectura" donde precisamente introduce sus cinco puntos como revisión a otros tantos conceptos de carácter no muy distinto.

Es una de sus frases la que, no exenta de contundencia, rubrique la impronta de este nuevo pensamiento:

\section{"La arquitectura es unos pisos iluminados" 34 .}

Y es que Le Corbusier, a pesar de no mencionar el término "técnica" a todo momento, hacía en cada una de sus manifestaciones clara alusión a ese espíritu de perfeccionamiento intrínseco en la máquina y la ciencia; lo que para él significaban elementos exactos y precisos. Cómo si no iluminamos pisos de no ser «por el auxilio de la técnica del hormigón y el acero que sustituyen el aspecto macizo del muro por la ligereza de los cerramientos especializados ${ }^{35}$, pues «las nuevas técnicas nos han traído nuevas palabras y las nuevas técnicas, a las que es imposible resistirse, llaman a nuestra imaginación» ${ }^{36}$.

No sólo nuevas palabras se dieron lugar en el atelier de Le Corbusier, sino también nuevas concepciones hasta entonces inéditas, aparecieron para quedarse y afianzar las bases sobre las que asentar la construcción de esta nueva forma de conocimiento en torno a la técnica.

\footnotetext{
${ }^{33}$ Le Corbusier: Précisions sur un état présent de l'architecture et de l'urbanisme. París: Éditions Vincent, Fréal et Cie, 1930. (Op cit. p. 120). Dentro del capítulo «Una célula a escala humana», donde apunta a la Cartuja d’Ema como fuente de inspiración de sus "inmuebles-villas".

${ }^{34}$ Ibídem. p. 69. Dentro del capítulo «Las técnicas son la base misma del lirismo. Abren un nuevo ciclo de la arquitectura».

${ }^{35}$ Torres, Jorge: Le Corbusier. Visiones de la técnica en cinco tiempos. Barcelona: Arquíthemas N¹3, 2004. p. 127. Donde se habla del arquitecto en torno a cinco tiempos: el progreso, la máquina, la técnica, la construcción y la infraestructura. En este caso concreto se refiere al tercero de ellos: "El ideal de la técnica: arquitectura y tecnología".

${ }^{36}$ Le Corbusier: Précisions sur un état présent de l'architecture et de l'urbanisme. París: Éditions Vincent, Fréal et Cie, 1930. (Op cit. p. 75). Dentro del capítulo «Las técnicas son la base misma del lirismo. Abren un nuevo ciclo de la arquitectura».
} 

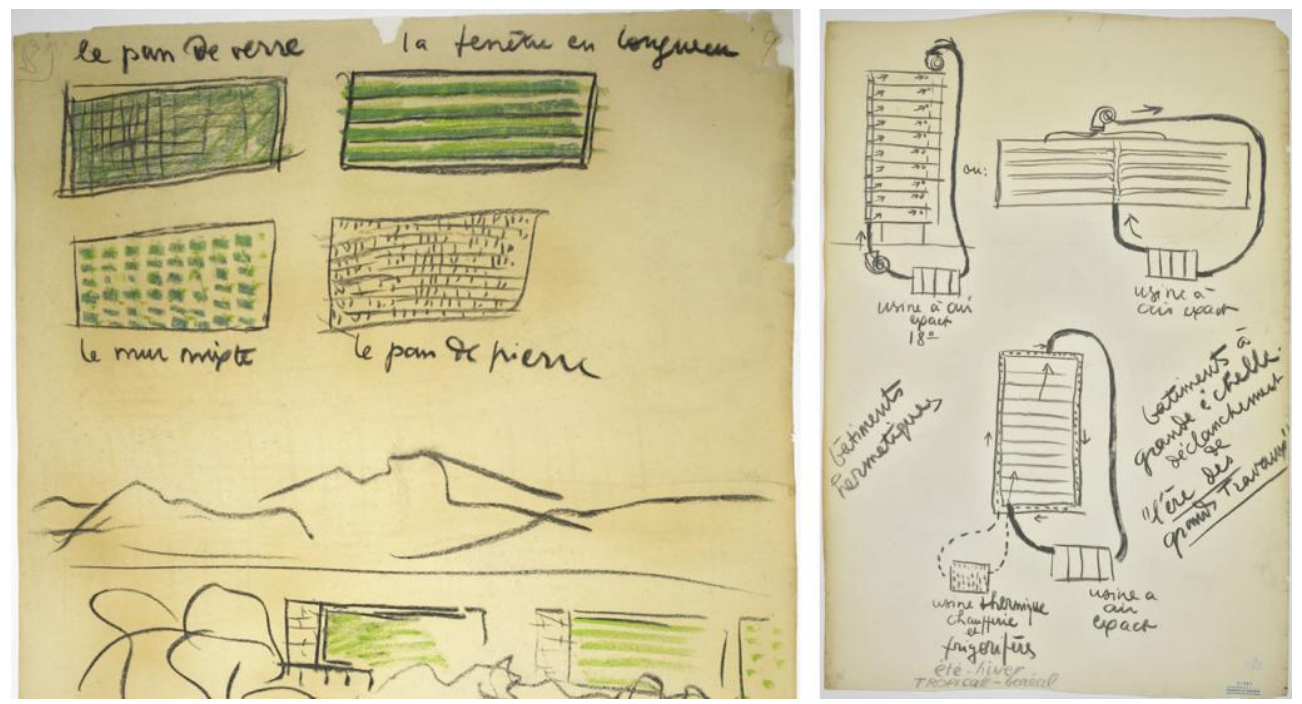

17. FLC_33504. Cuatro procedimientos para cerrar un espacio: le pan de pierre, le mur mixte, la fenêtre longeur y le pan verre - OFLC-ADAGP. // FLC_33527. Bocetos en los que el arquitecto presenta su edificio hermético - OFLC-ADAGP.

Entonces, si lo verdaderamente sustancial radica en iluminar los pisos de la arquitectura, no es de extrañar que sea ahí mismo el punto en el que el arquitecto suizo quisiera centrar su investigación; en esa membrana que, reducida ya por el piloti a la más extrema delgadez, se encargase de ajustar las discrepancias exteriores con las obligaciones propias del interior. Es por eso que la ventana corriente, entendida por el arquitecto como elemento económicamente impropio, se erija como protagonista de este nuevo discurso:

“Un buen día esta verdad aparece: “¡una ventana está hecha para dar luz, no para ventilar!”. Para ventilar, empleamos los aparatos de ventilación; es mecánica, es fisica”.

A lo que a continuación se pregunta:

“ ¿Y si pudiéramos, con un gesto, repudiar la ventana, pero dando, al mismo tiempo, luz a los pisos?”.

Hasta el punto de describir lo que sería el aspecto ideal de este, le pan de verre:

"El examen de mi perfil-símbolo me muestra unas fachadas reducidas a algunas bandas de cemento de 30 centímetros de altura. Bien, pasemos eso por alto, ipasemos adelante! Vamos a sujetar a 25 centímetros hacia delante e estas bandas de cemento, por medio de cartelas de llanta, unos hierros verticales, bien colocados, que tengan aplomo. Y a través, fuera o dentro, unos hierros horizontales a unas distancias proporcionadas a los cristales o a los vidrios disponibles en el comercio. Por consiguiente, delante de las fachadas habrá "un panel de vidrio". La fachada es un panel de cristal ${ }^{, 37}$.

Será pues el vidrio, hasta entonces confinado a los límites de la ventana, el encargado de otorgarle a la arquitectura ese nuevo cariz propio de las cosas transparentes y demostrar así, superada la timidez de épocas pretéritas, la vigencia de un material indudablemente versátil «capaz de resolver la escala arquitectónica desde la base a la cúspide, sin mudar su aspecto, alterar su diseño o modificar su naturaleza» ${ }^{38}$.

Es por eso que, a propósito de esta nueva "arquitectura de vidrio", no resulte extraña la exploración que Le Corbusier incorpora a sus composiciones pictóricas en las que este nuevo material, representado ahora por

\footnotetext{
${ }^{37}$ Ibídem. p. 73. (Fig. 17)

${ }^{38}$ Castellanos, Raúl: "Bloques de hormigón: la dignidad de lo normal”. En Catálogo Verni-Prens. 2010, 4ª edición. Valencia: General de Ediciones de Arquitectura. p. 19.
} 
aquellos elementos más cotidianos -sean botellas o vasos-, se diluya en un espectro de color fruto de la superposición que su propia transparencia autoriza.
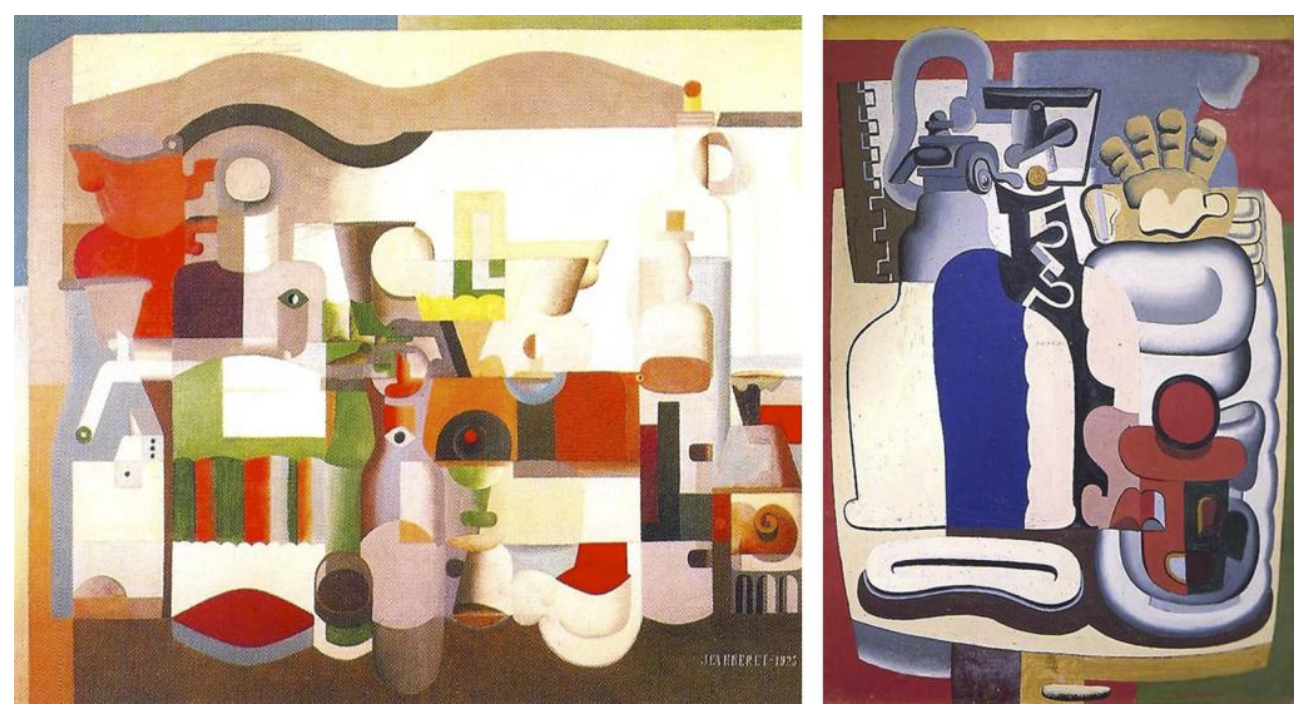

18. FLC_212. Jeanneret, Charles-Édouard: Nature morte au siphon. Óleo sobre lienzo (1,30 x 0,97 m.), 1928 - OFLCADAGP. // FLC_175. Nature morte aux nombreux objects. Óleo sobre lienzo (1,14 x 1,46 m.), 1923 - OFLC-ADAGP.

Sin embargo, no será hasta el momento de enfrentarse a sus grads travaux, allá por los años 30, cuando todos estos principios cobraron una importancia capital y se tiñeron de un cierto aire de universalidad. En este sentido pronuncia: «A esta hora de interpenetración general, de técnicas científicas internacionales, propongo: una sola casa para todos los países y para todos los climas: la casa con respiración exacta» ${ }^{39}$.

Principio este de la respiración exacta posiblemente originado, según Jorge Torres, como consecuencia del viaje que Le Corbusier realizó a Moscú en 1928 a propósito de la construcción del Centrosoyus, donde escribe una nota a Pierre Jeanneret diciendo:

"Pierre, revoir tout le système fenêtres. On pourrait éventuellement tout vitrer et chauffer entre deux. Consulter G. Lyon et laboratoire.

Etudier 1 chauffage à eau chaude pour bureaux - 1 chauffage à air chaud par doublé cloison vitrée pour empêcher le froid" 40 .

Tres años más tarde, y ya una vez construida la "respiración exacta" del Centrosoyus, será cuando Le Corbusier volviera a aquellos dos conceptos manuscritos para así poder incorporarlos a la futura construcción del Palacio de los Soviets, esto es, mediante la combinación de lo que pasó a denominarse "l'aeration ponctuelle" o sistema Gustave Lyon, encargado de la impulsión de aire; y "les murs neutralisants" o patente Le Corbusier y Pierre Jeanneret, entendidos como acristalamiento doble y hermético por cuyo interior habría de circular aire frío y caliente.

\footnotetext{
${ }^{39}$ Le Corbusier: Précisions sur un état présent de l'architecture et de l'urbanisme. París: Éditions Vincent, Fréal et Cie, 1930. (Op cit. p. 85). Dentro del capítulo «Las técnicas son la base misma del lirismo. Abren un nuevo ciclo de la arquitectura».

${ }^{40}$ En castellano (traducción del autor), "Pierre, revise todo el sistema de ventanas. Se podría eventualmente acristalarlo todo y calefactar entre dos. Consultar con G. Lyon y laboratorio. Estudiar 1 calefacción de agua caliente para oficinas - 1 calefacción de aire caliente por la doble pared de vidrio para evitar el frío". Fragmento referenciado por Jorge Torres en "Le Corbusier. Visiones de la técnica en cinco tiempos”. Barcelona: Arquíthemas No13, 2004. p. 133.
} 
"El principio dice tal que así: los "muros neutralizantes" con su circuito de aire tienen que mantener una temperatura constante de $18^{\circ}$ en la cara interior de las paredes de vidrio; mientras que en oficinas y anexos, necesitan de un circuito especial de ida y retorno -aireación puntual-que permitirá alimentar a todos los locales de aire puro a $18^{\circ}$ y humedad exacta; en las grandes salas, los mismos muros neutralizantes asegurarán la función aislante, mientras que la "aireación puntual” alimentará los pulmones de cada uno de los 6.000 o 15.000 espectadores, y es aquí donde el proceso se vuelve significativo" ${ }^{41}$.

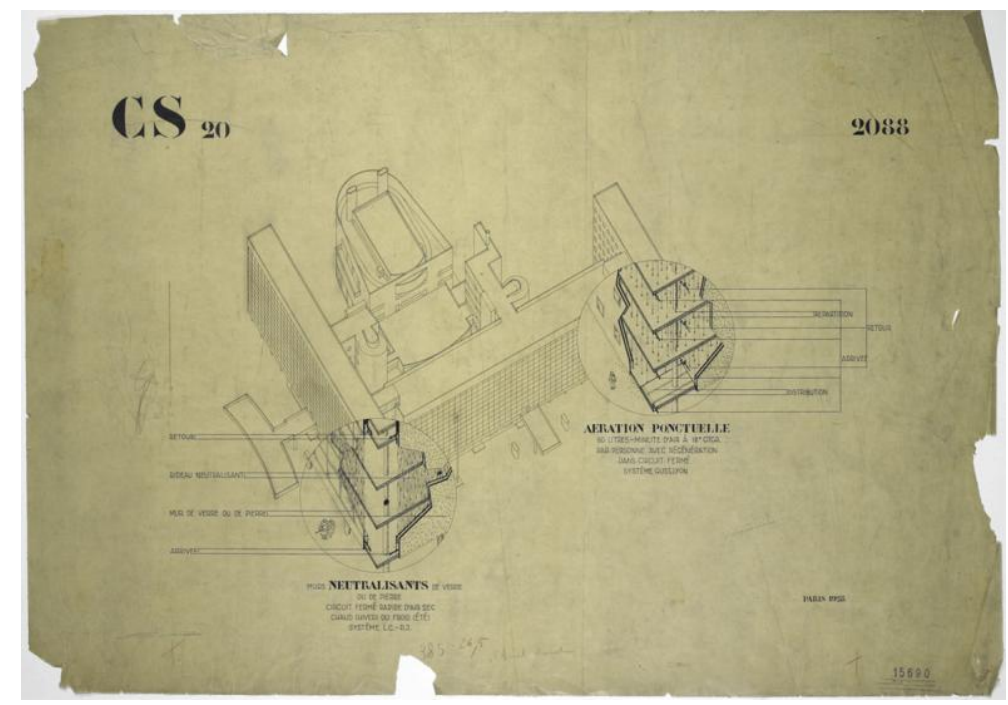

19. FLC_15690. Centrosoyus. Sistema de ventilación compuesto por murs neutralisants - aeration ponctuelle, 1928. Le Corbusier - Pierre Jeanneret - CFLC-ADAGP.

Es de esta manera como Le Corbusier, comprometido con su tiempo, haría de la técnica mera síntesis capaz de abarcar las aspiraciones propias de una antigüedad, que hasta entonces se supo incapaz de advertir tan invisible condición. Mudándola así en algo preciso, perfecto y exacto; un instrumento matemático y riguroso avezado ya en construir las leyes de su propia geometría.

\section{Coda}

Sirvan por tanto estas palabras como reunión a ciertas nociones que, auspiciadas por el proyecto de los Soviets, soportan las coordenadas en las que se encuadra la arquitectura de Le Corbusier. Allí donde la composición, al unísono con la simbología, la circulación y la técnica, constituyen el rudimento fundamental de estos, sus grandes trabajos; aquellos en los que el arquitecto nos desvela los entresijos de una promenade cuya forma resulta no ser nada más que materia resultante de su propio tiempo.

Será por tanto en el momento del quehacer, es decir, durante el desempeño de su actividad, cuando el arquitecto suizo, olvidándose de su propia existencia, dote a sus "volúmenes reunidos bajo la luz" de esa cuarta dimensión capaz de poner de acuerdo unos trazados que, multiplicados de manera incesante, parecen no querer nunca encontrar su propia conclusión.

\footnotetext{
${ }^{41}$ Le Corbusier; Jeanneret, Pierre: Projet pour la construction du Palais des Soviets à Moscou. Op cit. FLC_H3-6-1-029.
} 


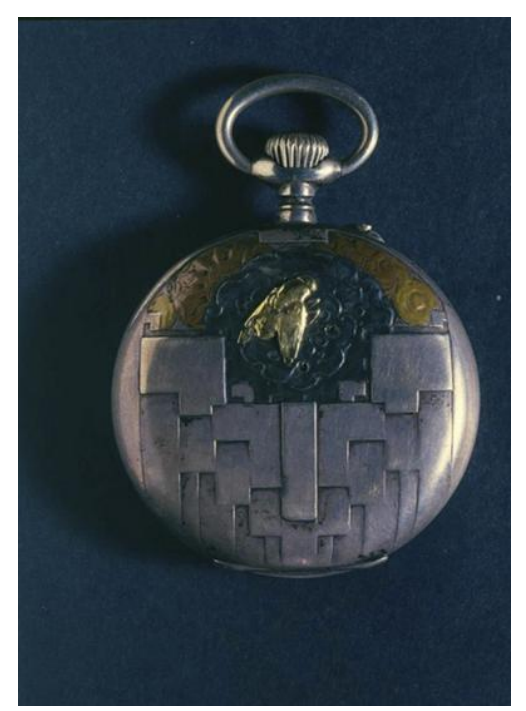

20. Reloj de bolsillo, expuesto en Milán, diseñado y grabado por Charles-Édouard Jeanneret en la Escuela de Arte de La Chaux-de-Fonds bajo la tutela de Charles L'Éplattenier (1874-1946), 1906. Fondation Le Corbusier - OFLC-ADAGP.

Y es que el tiempo, encapsulado por el niño en sus inicios, pasará a formar parte de esta arquitectura mudada ya en algo preciso: una suerte de cronómetro donde Le Corbusier, en suma, organiza formas que luchan por acordar su permanencia.

FIN

\section{Agradecimientos}

Este trabajo, iniciado hará algo más de un año, no es más que mera comunión de ciertas notas que en suma, terminarán por conformar la tesis doctoral a la que este escrito precede. Basten por tanto estas líneas para expresar mi gratitud a Jorge Torres, director de la tesis doctoral a la que se alude, por su paciencia y generosidad durante este tiempo.

\section{Créditos de las ilustraciones}

Chenal, Pierre: L'architecture d'aujourd hui. París: Película, 1929: 14abcd

Cohen, Jean-Louis: Le Corbusier et la mystique de I'URSS. Théories et projets pour Moscou 1928-1936. Bruselas y Lieja: Pierre Mardaga, 1987: 7a

Eisenstein, Serguéi: La línea general. Moscú: Película, 1929: 9a, 10a, 11abcd, 16c

Fernández Alba, Antonio y otros: Eugène Freyssinet. Un arquitecto revolucionario. Madrid: Fundación Esteyco, 2003: $7 \mathrm{bc}$

Fondation Le Corbusier (París): 1, 2abcd, 3abcd, 4b, 5ab, 6, 8, 9b, 10b, 12a, 13ab, 15, 16bd, 17ab, 18ab, 19, 20

IVAM. Centre Julio González: Naum Gabo y el concurso para el Palacio de los Soviets. Moscú 1931-1933. Berlín: Berlinische Galerie, 1993: 4a, 12b

Le Corbusier: Aircraft. Madrid: Abada Editores, 2003: 16c 


\section{Bibliografía}

Castellanos, Raúl: Plan Poché. Barcelona: Arquia/Tesis Nº 36, 2012.

Castellanos, Raúl: "Bloques de hormigón: la dignidad de lo normal". En Catálogo Verni-Prens. 2010, $4^{a}$ edición. Valencia: General de Ediciones de Arquitectura.

Cohen, Jean-Louis: Le Corbusier et la mystique de I'URSS. Théories et projets pour Moscou 1928-1936. Bruselas y Lieja: Pierre Mardaga, 1987.

Colomina, Beatriz: "Reflexiones sobre la casa Eames". En RA Revista de arquitectura. 2007, Nº. Pamplona: Servicio de publicaciones de la Universidad de Navarra.

Colquhoun, Alan: Modernidad y tradición clásica. Madrid: Júcar Universidad, 1991.

Fondation Le Corbusier: Le Corbusier. DVD Plans. París: Fondation Le Corbusier, 2010.

Froebel, Friedrich: La educación del hombre. Madrid: Daniel Jorro, Editor, 1913.

Klein, Alexander: Vivienda mínima: 1906-1957. Barcelona: Gustavo Gili, 1980.

Le Corbusier: Urbanisme. París: Éditions Vincent, Fréal et Cie, 1930.

Le Corbusier: Hacia una arquitectura. Barcelona: Poseidón, 1977.

Le Corbusier: Precisiones respecto a un estado actual de la arquitectura y el urbanismo. Barcelona: Poseidón, 1999.

Le Corbusier: Aircraft. Madrid: Abada Editores, 2003.

Torres, Jorge: Le Corbusier. Visiones de la técnica en cinco tiempos. Barcelona: Arquíthemas N¹3, 2004.

Torres, Jorge: "La arquitectura es la circulación". En Le Corbusier. Mise au point. Valencia: General de Ediciones de Arquitectura, 2012.

Zumthor, Peter: Pensar la arquitectura. Barcelona: Gustavo Gili, 2010. 